\title{
AVALIAÇÃO DA CITOTOXICIDADE, PROLIFERAÇÃO CELULAR E EXPRESSÃO GÊNICA DE MACRÓFAGOS E CÉLULAS INDIFERENCIADAS DA POLPA DENTÁRIA ESTIMULADAS COM PAPACÁRIE DUO ${ }^{\circledR}$
}
Dissertação apresentada à Faculdade de Odontologia de Ribeirão Preto da Universidade de São Paulo, para obtenção do Título de Mestre em Ciências.

Área de Concentração: Odontopediatria

Orientador: Dr. Francisco W. Garcia de Paula e Silva

\author{
Ribeirão Preto
}




\section{AUTORIZAÇÃO PARA REPRODUÇÃO}

Autorizo para reprodução e divulgação total ou parcial deste trabalho por qualquer meio convencional ou eletrônico, para fins de estudo e pesquisa, desde que citada a fonte.

\section{FICHA CATALOGRÁFICA}

Bastos, Laura Alves

Avaliação da Citotoxicidade, Proliferação Celular e Expressão Gênica de Macrófagos e Células Indiferenciadas da Polpa Dentária Estimuladas com Papacárie Duo ${ }^{\circledR}$. Ribeirão Preto, 2016.

83p. : il. ; $30 \mathrm{~cm}$

Dissertação de Mestrado apresentada à Faculdade de Odontologia de Ribeirão Preto/USP - Área de Concentração: Odontopediatria.

Orientador: Paula-Silva, Francisco Wanderley Garcia de

1. Citotoxicidade. 2. Diferenciação celular. 3. Células pulpares. 4. Papacárie Duo ${ }^{\circledR}$. 5. Macrófagos. 6. Mediadores Inflamatórios. 7. Remoção químico-mecânica da cárie. 
Bastos LA. Avaliação da Citotoxicidade, PROLIferaçÃo CelULAR E EXPRESSÃo GÊNiCA de MACRÓFAGOS E CÉLULAS INDIFERENCIADAS DA POLPA DENTÁRIA ESTIMULADAS COM PAPACÁRIE DUO $^{\circledR}$

Dissertação apresentada à Faculdade de Odontologia de Ribeirão Preto da Universidade de São Paulo, para obtenção do Título de Mestre em Ciências.

Área de Concentração: Odontopediatria

Data da defesa:

1

\section{Banca Examinadora}

Prof. Dr.

Instituição:

Julgamento:

Assinatura:

Prof. Dr.

Instituição:

Julgamento:

Assinatura:

Prof. Dr.

Instituição:

Julgamento:

Assinatura: 



\section{DADOS CURRICULARES}

\section{LAURA ALVES BASTOS}

Nascimento 25 de outubro de 1990 - Araraquara/SP

Filiação Pedro Bastos

Valderes Alves Bastos

2009-2012 Curso de Graduação (Universidade de São Paulo) Faculdade de Odontologia de Ribeirão Preto

Iniciação científica: Influência do tipo de sistema adesivo na resistência de união de compósito à base de silorano ao substrato dentinário

Orientada pela Professora Doutora Fernanda de Carvalho Panzeri Pires-de-Souza e pelo Professor Doutor Lucas da Fonseca Roberti

2014-2015 Curso de Aperfeiçoamento

Atendimento Odontológicos a Pacientes Especiais (Universidade de São Paulo) Faculdade de Odontologia de Ribeirão Preto

2014-2017 Curso de Aperfeiçoamento em Ortodontia Centro de Ortodontia Ortogotardo

2014-2016 Curso de Pós-Graduação em Odontopediatria, nível Mestrado (Universidade de São Paulo) Faculdade de Odontologia de Ribeirão Preto 

Trabalho realizado com apoio financeiro do Programa de Auxílio à Pesquisa Jovem Pesquisador (processo 2010/17611-4), concedido pela Fundação de Amparo à Pesquisa do Estado de São Paulo (FAPESP) e Bolsa de Mestrado concedida pela Coordenação de Aperfeiçoamento de Pessoal de Nível Superior (CAPES). 

Dedicatória 



\section{DEDICO ESTE TRABALHO}

À Deus por mais essa conquista. Pelas oportunidades e pelas pessoas maravilhosas que colocou em meu caminho. Peço à Ele que me dê sabedoria e guie meus caminhos para conquistar ainda mais! "Confie na força de Deus e você seráa abençoado"

Aos meus queridos pais...

Pedro Bastos e Valderes Alves Bastos, pelo exemplo, pelo apoio em todas as minhas decisões, pela torcida para que tudo desse certo, pelo carinho e oportunidades que me ofereceram desde sempre. Mesmo distantes sempre estão dispostos a ajudar, são meu porto seguro. Vocês fizeram de mim a pessoa que hoje sou, e eu só tenho motivos para agradecer. Tudo que conquistei até aqui, são graças à vocês! Muito Obrigada!

À minha irmã, Mariana Alves Bastos, pelo companheirismo, pela confiança, pelos anos de vida compartilhada, de momentos de alegria, de bagunças e brigas, de choros e gritos, de sorrisos e cumplicidades que juntas vivemos.

Aos meus familiares, tios, tias, primos, avós, que estão sempre ao meu lado e torcem tanto por mim! 

Agradecimento Especial 



\section{AGRADECIMENTO ESPECIAL}

Ao meu querido orientador, Dr. Francisco Wanderley Garcia de Paula e Silva,

pelos ensinamentos nesses dois anos, pela dedicação, pela paciência, apoio, cuidado, humildade e pela amizade. Um dos maiores presentes foi poder trabalhar com você, uma pessoa tão sábia e admirāvel. Sempre acessivel e muito atencioso, soube despertar minha admiração de um modo único, e se tornou uma inspiração para mim. Muito Obrigada!

"Palavras sábias ao relento do abrigo dos que crescem." 

Agradecimentos 



\section{AGRADECIMENTOS}

À Faculdade de Odontologia de Ribeirão Preto da Universidade de São Paulo, na pessoa da atual diretora Profá. Drá. Léa Assed Bezerra da Silva e à Coordenação do Curso de Pós-Graduação em Odontopediatria da Faculdade de Odontologia de Ribeirão Preto da Universidade de São Paulo, na pessoa da Profa. Dra Raquel Assed Bezerra Segato.

Ao Prof. Dr. Paulo Nelson-Filho, pela riqueza de seus ensinamentos, mostrando a essência de um verdadeiro Mestre. Obrigada pelo exemplo!

Ao corpo docente do Departamento de Clínica Infantil da Faculdade de Odontologia de Ribeirão Preto da Universidade de São Paulo, Prof́. Dra . Léa Assed Bezerra da Silva, Profa. Dra. Aldevina Campos de Freitas, Prof. Dr. Paulo Nelson-Filho, Profa. Dra Alexandra Mussolino de Queiroz, Prof. Dr. Fabrício Kitazono de Carvalho, Profa. Dra. Kranya Victória Díaz-Serrano, Profa. Dra . Maria Cristina Borsatto, Profá. Dra . Raquel Assed Bezerra Segato, Profa. Dra. Andiara de Rossi Daldegan, Prof ${ }^{a}$. Dra. Mírian Aiko Nakane Matsumoto, Profa. Dra. Maria Bernadete Sasso Stuani, Prof. Dr. José Tarcísio Lima Ferreira, Prof. Dr. Adilson Thomazinho, Prof. Dr. Fábio Lourenço Romano e Profa. Dra. Maria da Conceição Pereira Saraiva pela convivência agradável e por todo ensinamento a mim transmitido. Obrigada pelas inúmeras vezes que se disponibilizaram em me auxiliar de alguma forma.

À Profa. Dra Lucia Helena Faccioli, por abrir as portas do Laboratório de Imunologia e Inflamação das Parasitoses (LIIP) e a todos os seus pós-graduandos, que me 
ajudaram de alguma forma durante a fase em que estive em experimento no laboratório, em especial à Caroline Fontanari e Alyne Galvão.

Aos meus colegas de grupo de pesquisa, Daniele Lucca Longo, Fernanda Regina Ribeiro dos Santos, Igor Bassi Ferreira Petean, Mariana de Oliveira Daltoé e em especial Francine Lorencetti pela ajuda nos meus primeiros passos em experimentos laboratoriais.

Às minhas amigas queridas e tão parceiras de turma Thaís Aparecida Xavier, Nicole Lima, Raquel Morelli e Claudia Carpio, pela amizade e companheirismo nesses anos, pelos conselhos, apoio e confiança. Levarei vocês por toda vida.

Aos mais novos colegas de turma que já fazem parte da minha vida, agradeço pela amizade, Ana Maria Guerra, Alessandra Parreira Menino, Mariana Trevizan, Mariana Shirozaki, Guido Vasquez, Arthur Cunha, Ana Paula Dias, Thaise Taira, Letícia Sgarbi Pinto.

Aos veteranos de turma Sofia Sampaio Meireles de Souza, Mariana de Oliveira Daltoé, Juliana Arid, Francine Lorencetti Silva, Carolina Maschietto Pucinelli, Silvana Polizeli, Marilia Moreira, Rodrigo Alexandre Valério, Driely Barreiros, Patrícia Maria Monteiro, Sara Silva de Oliveira, Leonardo Gontijo Matos, Daniele Lucca Longo, Ana Carolina Fumes, Denise de Souza Matos, Karina Grecca Pieroni, Katharina Morant Holanda de Oliveira, Mariana Alencar Namezio, Priscilla Coutinho Romualdo, Danielly Cunha Araújo Ferreira, Daniela Barroso, Lídia Hidalgo, Talitha de Siqueira Mellara, Marina 
Moscardini Vilela, Paula Regina Ávila Silvano, Maria Gabriela Flores Bracho, Elaine Machado Pingueiro, Larissa Nogueira Soares Ribeiro, Mariele Andrade, pelo exemplo, aprendizado e momentos compartilhados.

Aos funcionários do Departamento de Clínica Infantil e da Clínica de Pacientes Especiais da Faculdade de Odontologia de Ribeirão Preto da Universidade de São Paulo, Filomena Lelli Placciti, Matheus Morelli Zanela, Micheli Cristina Leite Rovanholo, Rosemary Alves, Vera do Nascimento Scandelai, Benedita Viana Rodrigues, Renata Cristina Rosa e Fătima Aparecida Rizoli pela ajuda, sempre muito atenciosos.

Às funcionárias da Seção de Pós-Graduação da Faculdade de Odontologia de Ribeirão Preto da Universidade de São Paulo Isabel Cristina Galino Sola e Mary Possani pela disposição e atenção que sempre deram a mim.

À Marilia Pacífico Lucisano e Carolina Paes Torres Mantovani pelo exemplo de profissionais, sempre muito atenciosas e simpáticas.

À Nilza Letícia Magalhães, sempre disposta a ajudar, colaborando para os meus experimentos.

Aos amigos e amigas que são muito especiais para mim, Marina Dantas, Raiane Azevedo, Raissa Azevedo, Rafaela Azevedo, Sonara Piassi, Suelen Teles, Paulo Malvar, 
Mayara Semeghini, Laisa Silva, Ana Beatriz Vilela. Momentos maravilhosos foram compartilhados com vocês. Obrigada pelo carinho de sempre.

Aos meus amigos da querida Turma 84 !

À CAPES (Coordenação de Aperfeiçoamento de Pessoal de Nivel Superior) e à FAPESP (Fundação de Amparo à Pesquisa do Estado de São Paulo), pelo apoio financeiro concedido para o desenvolvimento desta pesquisa 
Sumário 



\section{SUMÁRIO}

\section{RESUMO}

\section{ABSTRACT}

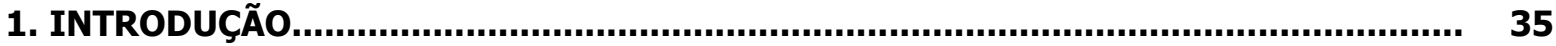

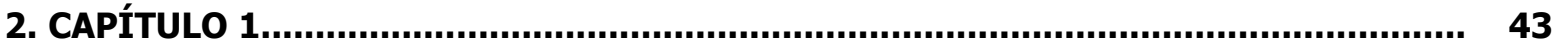

AVALIAÇÃO DO EFEITO DO PAPACÁRIE DUO ${ }^{\circledR}$, UM GEL USADO PARA REMOÇÃO QUÍMICO-MECÂNICA DO TECIDO CARIADO, EM CÉLULAS DA POLPA DENTAL

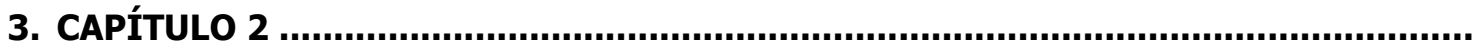
PAPACÁRIE DUO ${ }^{\circledR}$ INDUZ A ATIVAÇÃO DE MACRÓFAGOS E EXPRESSÃO DE MEDIADORES INFLAMATÓRIOS

4. CONCLUSÕES. 



Resumo





\section{RESUMO}

Bastos LA. Avaliação da Citotoxicidade, Proliferação Celular e Expressão Gênica de Macrófagos e Células Indiferenciadas da Polpa Dentária Estimuladas com Papacárie Duo®. [Dissertação]. Ribeirão Preto: Universidade de São Paulo, Faculdade de Odontologia de Ribeirão Preto, 2016. 83p.

O tratamento minimamente invasivo tem sido cada vez mais empregado no tratamento das lesões de cárie dental, especialmente em crianças jovens. Com isso, a remoção do tecido cariado pelo método químico-mecânico permite uma maior conservação das estruturas dentais saudáveis. O Papacárie Duo ${ }^{\circledR}$ é um material de fácil aplicação e possui propriedades bactericidas e anti-inflamatórias. Este material é aplicado sobre a dentina cariada, a fim de promover um amolecimento desta, facilitando a sua remoção. Os efeitos celulares de Papacárie Duo ${ }^{\circledR}$ são pouco conhecidos, dessa forma esta pesquisa teve como objetivo avaliar o efeito do Papacárie Duo ${ }^{\circledR}$ em células indiferenciadas da polpa dental (Capítulo 1) e a capacidade do Papacárie Duo ${ }^{\circledR}$ induzir a ativação de macrófagos e a síntese de mediadores inflamatórios (Capítulo 2). O Papacarie Duo ${ }^{\circledR}$ foi preparado nas concentrações de 0,5 e 5\% por meio de diluição seriada, a partir do gel obtido comercialmente. Células OD-21 e macrófagos $\mathrm{J774.1}$ foram mantidas em cultura com os diferentes tratamentos por um período de estimulação de 24 horas para realização do teste de citotoxicidade (Ensaio LDH) e por 36 horas para avaliação da proliferação celular (Ensaio Colorimétrico MTT). A seguir foi realizada avaliação da expressão gênica relativa dos genes Ibsp, Runx2 e Spp1 em células OD-21; e dos genes I/10, Mmp9, Ptgs2 e Tnf em células J774.1, pelo método de transcrição reversa e reação em cadeia de polimerase em tempo real (qRT-PCR), utilizando o sistema $\operatorname{TaqMan}^{\circledR}$ após estimulação o período de 24 horas. O Papacárie Duo ${ }^{\circledR}$ a $5 \%$ foi citotóxico às células da polpa dental e inibiu a proliferação celular, assim como a expressão de Runx 2 e Ibsp. Porém em ambas as concentrações estimulou a expressão de Spp1, a qual foi maior na concentração de $5 \%$. Em macrófagos, o Papacárie Duo ${ }^{\circledR}$ foi citotóxico na concentração de $5 \%$, mas não influenciou a proliferação celular em nenhuma das concentrações (0,5 e 5\%). O LPS inibiu a proliferação celular na presença ou não de Papacárie Duo $R$, sem apresentar citotoxicidade. O Papacárie Duo ${ }^{\circledR}$ induziu a expressão de Ptgs2 e I/10, sem alterar Tnf e Mmp9. Portanto, o Papacárie Duo ${ }^{\circledR}$ foi citotóxico, dependendo da concentração, e apresentou efeito inibitório na diferenciação de células da polpa (OD-21), sem entretanto influenciar a proliferação celular. Papacárie Duo ${ }^{\circledR}$ não impediu a proliferação de macrófagos, porém foi citotóxico na concentração de $5 \%$ mas não à $0,5 \%$. Adicionalmente, Papacárie Duo ${ }^{\circledR}$ modulou a ativação de macrófagos pela indução da expressão de Ptgs2 e I/10, sem alterar a expressão de Tnfe Mmpg.

Palavras-chave: Citotoxicidade, Diferenciação celular, Células pulpares, Papacárie Duo ${ }^{\circledR}$, Macrófagos, Mediadores Inflamatórios, Remoção químico-mecânica da cárie. 

Abstract 



\begin{abstract}
Bastos LA. Cytotoxicity, Cell Proliferation and Gene Expression of Macrophages and Undifferentiated Cells From Dental Pulp Stimulated with Papacárie Duo ${ }^{\circledR}$ [Dissertation]. Ribeirão Preto: University of São Paulo, School of Dentistry of Ribeirão Preto, 2016. 83p.
\end{abstract}

The minimally invasive treatment has been increasingly used in the treatment of dental caries, particularly in young children. Thus, the removal of carious tissue by chemicalmechanical method allows greater conservation of healthy tooth structure. The Papacárie Duo $^{\circledR}$ is an easily applied material, and has bactericidal and anti-inflammatory properties. This material is applied over the carious dentin in order to promote a softening thereof, facilitating its removal. The cellular effects of Papacárie Duo ${ }^{\circledR}$ are little known, therefore this research was to evaluate the effect of Papacárie Duo ${ }^{\circledR}$ in undifferentiated cells from dental pulp (Chapter 1) and the capacity of Papacárie Duo ${ }^{\circledR}$ to induce macrophage activation and synthesis inflammatory mediators (Chapter 2). The Papacárie Duo ${ }^{\circledR}$ was prepared at concentrations of 0.5 and $5 \%$ by serial dilution from the gel obtained commercially. OD- 21 cells and 3774.1 macrophages were maintained in culture with the different treatments for a period of 24 hours to perform the cytotoxicity assay (LDH assay) and for 36 hours for evaluation of cell proliferation (MTT colorimetric assay). The following, was carried out the assessment of the relative gene expression of Ibsp, Runx2 and Spp1 genes in OD-21 cells, and I/10, Mmp9, Tnf and Ptgs2 in 3774.1 cells by reverse transcription method and reaction in real time polymerase chain reaction ( $\mathrm{qRT}$-PCR) using the TaqMan system after the stimulation period of 24 hours. The $5 \%$ Papacárie Duo $®$ was cytotoxic to cells of dental pulp and inhibited cell proliferation and the expression of Runx2 and Ibsp. However, in both concentrations stimulated the expression of Spp1, which was higher at a concentration of $5 \%$. In macrophages, the Papacárie Duo ${ }^{\circledR}$ was cytotoxic at concentrations of $5 \%$, but did not affect the cell proliferation in any of the concentrations (0.5 and 5\%). LPS inhibited cell proliferation in the presence or absence of Papacárie Duo ${ }^{\circledR}$ without giving cytotoxicity. The Papacárie Duo ${ }^{\circledR}$ induced the expression of Ptgs2 and I/10, without changing Tnf and Mmp9. Therefore, the Papacárie Duo ${ }^{\circledR}$ was cytotoxic, depending on the concentration, and showed inhibitory effect on the differentiation of pulp cells (OD-21), but without influencing cell proliferation. Papacárie Duo ${ }^{\circledR}$ not prevent macrophage proliferation, but was cytotoxic at a concentration of $5 \%$ but not more than $0.5 \%$. Additionally, Papacárie Duo ${ }^{\circledR}$ modulated the activation of macrophages by inducing I/10 and Ptgs2 expression without altering the expression of Tnf and Mmp9.

Keywords: Cytotoxicity, Cell differentiation, Dental pulp, Papacárie Duo ${ }^{\circledR}$, Macrophages, Inflammatory mediators, Chemo-mechanical caries removal method. 

1. Introdução 



\section{INTRODUÇÃO}

A remoção do tecido cariado pelo método convencional, ou seja, através de brocas em alta e baixa velocidade, normalmente induz dor, ruídos e vibração, além de efeitos térmicos e de pressão que podem ser prejudiciais ao tecido pulpar (Bussadori et al., 2005). Este é então um dos grandes desafios da Odontologia, principalmente em relação aos pacientes fóbicos, especiais e crianças (Ericson et al., 1999; Beeley et al., 2000; Chowdhry et al., 2015). Portanto, diversas alternativas estão sendo desenvolvidas para tentar minimizar a percepção desagradável pelo paciente durante a remoção da cárie, além da tentativa de maior preservação dos tecidos sadios. Por meio dessa visão de mínima intervenção e máxima preservação dos tecidos dentários, é necessário a distinção clínica da dentina que deverá ser removida (dentina infectada), daquela remineralizável, que poderá ser preservada (dentina afetada). (Massara et al., 2002)

A dentina infectada é a camada mais externa do tecido cariado, amolecida, necrótica e extremamente contaminada, enquanto a dentina afetada está localizada mais internamente, abaixo da dentina necrótica, sendo menos contaminada e desorganizada e com capacidade de remineralização (Fusayama, 1979; Kuhn et al., 2014).

Alguns métodos que removem seletivamente a dentina cariada são conhecidos como, a remoção químico-mecânica, o tratamento restaurador atraumático (TRA), brocas de polímeros e a irradiação com laser. O sucesso destas terapias baseia-se na seletividade da remoção do tecido cariado, a qual reduz a quantidade de bactérias no interior da cavidade sem remover o tecido cariado passível de remineralização (Martins et al., 2009).

Os estudos sobre a remoção químico-mecânica dos tecidos cariados surgiram nos Estados Unidos da América na década de 1970 quando Goldman e Kronman (Goldman, Kronman, 1976) estudando os efeitos do hipoclorito de sódio a $5 \%$ descobriram que este era capaz de promover a dissolução de dentina cariada (Beeley et al., 2000). Porém, mais tarde, 
notou-se que este material era muito instável e corrosivo para uso em tecidos saudáveis (Goldman, Kronman, 1976). Na tentativa de minimizar estes problemas, uma solução conhecida como Sorensen que continha glicina, cloreto de sódio e hidróxido de sódio, foi incorporada ao hipoclorito de sódio a $5 \%$ e o produto resultante, a $\mathrm{N}$-monocloroglicina (NMG) a 0,05\% também denominada de GK101 provou ser eficaz na remoção de tecido cariado. Tentativas de melhorias nessa solução foram realizadas e esta foi sucedida pela GK101 E (Beeley et al., 2000).

Somente na década de 1980, após os avanços nos estudos sobre remoção químicomecânica da cárie, foi autorizado o uso da solução GK101 E, que ficou conhecida como Caridex $^{\mathrm{TM}}$ (National Patent Medical Products Inc., New Jersey, USA). Porém, devido às desvantagens apresentadas como o alto custo, procedimento lento, curta validade clínica e necessidades de grandes volumes de material tornando-o de baixa praticidade, esse produto deixou de ser comercializado (Beeley et al., 2000).

Tentando superar as desvantagens do sistema Caridex ${ }^{\mathrm{MM}}$, um novo produto foi desenvolvido na década de 1990 na Suécia. Carisolv ${ }^{\mathrm{TM}}$ (MediTeam Dentalutveckling $A B$, Savedelen Sweden) era composto por duas bisnagas, uma contendo um gel de lisina, glicina, leucina, ácido glutâmico, cloreto de sódio, eritrosina e carboximetilcelulose, e outra contendo hipoclorito de sódio a 0,5\% (Ericson et al., 1999). Posteriormente, Carisolv ${ }^{\mathrm{TM}}$ foi desenvolvido em uma única seringa, com os mesmos componentes, facilitando seu uso e aumentando a sua durabilidade. Apesar da eficácia na remoção de tecido cariado, Carisolv ${ }^{\top \mathrm{M}}$ necessita de instrumentos específicos, tornando o produto inconvenientemente com custo mais elevado (Martins et al., 2009).

Diante da necessidade de um produto mais acessível para a aplicação do método químico-mecânico na remoção do tecido cariado, uma nova fórmula foi desenvolvida por pesquisadores brasileiros em 2003 (Bussadori et al., 2005) e aprimorado ao longo dos anos. Disponível atualmente no comércio brasileiro, o Papacárie Duo® (Fórmula \& Ação, São 
Paulo, SP, Brasil) é composto basicamente por papaína, cloramina, azul de toluidina, sais e veículo de espessamento, o que confere ações anti-inflamatórias, bactericida e bacteriostática ao produto (Bussadori et al., 2005). O principal componente, a papaína, vem do látex das folhas e frutos do papaia adulto e é muito utilizada em alimentos, bebidas, medicamentos e nas indústrias (Kimmel et al., 1954; Kimmel et al., 1957). É utilizada há tempos na cicatrização de feridas devido ao seu poder de desbridamento químico, granulação e epitelização dos tecidos (Mandelbaum et al., 2003). Já a cloramina também é um componente fundamental devido à suas propriedades bactericida e antisséptica (Nagl et al., 2003). Ela também possui uma capacidade importante de suavizar quimicamente a dentina cariada, facilitando a sua remoção (Maragakis et al., 2001). O Papacárie não requer instrumentos específicos para sua utilização, tornando-o prático, acessível e de baixo custo.

Devido a íntima relação entre dentina e tecido pulpar, todas as injúrias impostas à essa dentina podem repercutir ao tecido conjuntivo pulpar subjacente (Orchardson e Cadden, 2001). A dentina é permeada por túbulos que convergem à medida que caminham para áreas dentinárias mais internas e, portanto, o diâmetro dos túbulos dentinários varia em função da distância em relação à superfície da câmara coronária (Pashley e Carvalho, 1997). Assim, materiais aplicados sobre o complexo dentino-pulpar podem ser biocompatíveis se aplicados sobre cavidades rasas e de média profundidade onde a permeabilidade da dentina é menor, porém podem apresentar efeitos indesejáveis ao tecido pulpar quando em cavidades mais profundas, pois a espessura e as características morfológicas da dentina remanescente favorecem a difusão transdentinária dos componentes químicos dos materiais, os quais podem ser tóxicos ao tecido pulpar ou ainda interferir negativamente no processo de reparo (Marshall et al., 1997). Dessa maneira, considerando a proximidade entre o material aplicado e o tecido pulpar subjacente, principalmente em cavidades profundas, existe a necessidade de avaliar o comportamento biológico dos materiais odontológicos frente às células pulpares, pois agressões ao tecido 
pulpar podem ser causadas por metabólitos provenientes de micro-organismos envolvidos com infecções bacterianas como a cárie ou por componentes que são liberados desses produtos.

A polpa dental é composta estruturalmente por fibras de tecido conjuntivo, líquido intersticial, nervos, tecido vascular, odontoblastos, células mesenquimais indiferenciadas, macrófagos, linfócitos e outros componentes celulares menores (Abd-Elmeguid e Yu, 2009). Durante um processo inflamatório, macrófagos, que são células que participam da reação de defesa, são recrutados para o processo de fagocitose e liberam mediadores químicos, que são responsáveis pela destruição tecidual local, necessária para a chegada do aporte de células de defesa bem como paro o reparo tecidual (Okiji et al., 1992; Murray e Wynn, 2011). Quando estimulados por fatores externos tais como o lipopolisacarídeo (LPS) da parede de bactérias gram-negativas ou por fatores endógenos como o interferon gama, produzido por linfócitos T, os macrófagos têm suas funções bastante aumentadas, tornandose células ativadas. Um macrófago ativado aumenta de tamanho e volume, adere fortemente às superfícies e produz grandes quantidades de mediadores biológicos pró e antiinflamatórios, aumentando a capacidade de fagocitose (Metzger, 2000; Murray e Wynn, 2011).

Os odontoblastos são células que frente à injúrias pulpares, passam a produzir matriz dentinária próxima aos locais lesados na tentativa de proteger o tecido pulpar da infecção microbiana (Charadram et al., 2013). A capacidade de resposta do complexo dentino-pulpar ocorre graças à estimulação desses odontoblastos, que sintetizam e secretam a matriz dentinária reacional. Esse processo de reparação do tecido ocorre também com a participação de citocinas pró-inflamatórias, fatores de crescimento, componentes da matriz extracelular e outras moléculas biologicamente ativas (Paula-Silva et al., 2009; Bleicher, 2014). Por outro lado, em quadros pulpares inflamatórios intensos, a deposição de dentina reacional pelos odontoblastos pode ser cessada e o reparo dentinário realizado a partir de 
células-tronco presentes na polpa dental (Cooper et al., 2010; Bleicher, 2014). Diante da morte de odontoblastos, as células indiferenciadas da polpa dental têm seu comportamento e potencial de diferenciação afetados, e são capazes de diferenciação em células denominadas odontoblast-like ou células semelhantes a odontoblastos, as quais passam a secretar matriz dentinária e depositá-la sob a forma de dentina reparadora (Teclès et al., 2005; Yalvac et al., 2010; Chogle et al., 2012; Chmilewsky et al., 2014). O tecido pulpar, então, se revela um ambiente com ampla capacidade de reparo, especialmente por apresentar células progenitoras e vias de sinalização de reparo induzidas pela dissolução da dentina cariada, o que gera a secreção de mediadores que propiciam a secreção de dentina reparadora, neoangiogênese e inervação (Chmilewsky et al., 2014).

Nesse sentido, é essencial avaliar o efeito de materiais indicados para a remoção químico-mecânica da cárie quanto ao potencial de induzir a formação de dentina de reparação e inflamação pulpar. Diante do exposto, esta pesquisa teve como objetivo avaliar o efeito do Papacárie Duo ${ }^{\circledR}$ em células indiferenciadas da polpa dental (Capítulo 1) e a capacidade do Papacárie Duo ${ }^{\circledR}$ induzir a ativação de macrófagos e a síntese de mediadores inflamatórios (Capítulo 2). 

2. Capitulo 1 



\section{Avaliação do efeito do papacárie duo ${ }^{\circledR}$, um gel usado para remoção QUÍMICO-MECÂNICA DO TECIDO CARIADO, EM CÉLULAS DA POLPA DENTAL}

Diante da visão de mínima intervenção e máxima preservação dos tecidos dentários durante a remoção do tecido cariado, alguns métodos tornam-se mais conhecidos e estão sendo aprimorados (Hamama et al., 2015). A remoção químico-mecânica do tecido cariado tem sido estudada e o sucesso desta terapia baseia-se na seletividade da remoção do tecido cariado, a qual reduz a quantidade de bactérias no interior da cavidade sem remover o tecido passível de remineralização (Fusayama, 1979; Martins et al., 2009). Este método é ainda capaz de minimizar a percepção desagradável pelo paciente durante a remoção da cárie pelo método convencional, e, portanto, vem sendo amplamente aceito entre os pacientes fóbicos, crianças e especiais (Ericson et al., 1999; Beeley et al., 2000; Chowdhry et al., 2015).

O Papacárie Duo ${ }^{\circledR}$ é um dos materiais desenvolvidos para remoção químico-mecânica da cárie, sucedendo o Sistema Caridex ${ }^{\mathrm{TM}}$ e Carisolv ${ }^{\mathrm{TM}}$. Ele é composto basicamente por uma enzima proteolítica que interage com o colágeno parcialmente degradado do tecido cariado necrosado, e é também prático e acessível (Bussadori et al., 2005). Entretanto, ainda não existem trabalhos que avaliaram o efeito deste material em cavidades profundas e em células indiferenciadas da polpa dental. Estes estudos são importantes para definir se a remoção químico-mecânica da cárie influencia os processos de diferenciação celular e mineralização.

Devido a íntima relação entre dentina e tecido pulpar, todas as injúrias impostas à essa dentina repercutem instantaneamente à polpa (Orchardson and Cadden, 2001). A dentina é permeada por túbulos que convergem à medida que caminham para áreas dentinárias mais internas e, portanto, o diâmetro dos túbulos dentinários varia em função da distância em relação à superfície da câmara coronária (Pashley e Carvalho, 1997). Assim, 
materiais aplicados sobre o complexo dentino-pulpar podem ser biocompatíveis se aplicados sobre cavidades rasas e de média profundidade onde a permeabilidade da dentina é menor, porém podem apresentar efeitos indesejáveis ao tecido pulpar quando em cavidades mais profundas, pois a espessura e as características morfológicas da dentina remanescente favorecem a difusão transdentinária dos componentes químicos dos materiais, os quais podem ser tóxicos ao tecido pulpar ou ainda interferir negativamente no processo de reparo (Marshall et al., 1997). Dessa maneira, considerando a proximidade entre o material aplicado e o tecido pulpar subjacente, principalmente em cavidades profundas, nosso estudo avaliou o efeito do Papacárie na citotoxicidade, proliferação e diferenciação de células indiferenciadas da polpa dentária (OD-21).

\section{MATERIAL E MÉTODOS}

\section{Cultura celular}

Para esse estudo, foram utilizadas células indiferenciadas da polpa dentária de camundongos (OD-21), gentilmente cedidas pela Professora Doutora Karina Fittipaldi Bombonato Prado do Departamento de Morfologia, Fisiologia e Patologia da Faculdade de Odontologia de Ribeirão Preto da Universidade de São Paulo (FORP-USP).

Estas células foram mantidas congeladas em vial acondicionado em nitrogênio líquido (criopreservação) e conservadas em solução de congelamento composta por $90 \%$ de Soro Fetal Bovino (FBS; Gibco, Carlsbad, CA, EUA) e 10\% de Dimetilsulfóxido (DMSO) (Mallinckodt Chemicals, Mallinckrodt Baker Inc., Phillipsburg, EUA) até início da cultura.

As células foram descongeladas e o conteúdo presente no via/foi transferido para um tubo cônico (Falcon ${ }^{\mathrm{TM}}$, Corning Inc., NY, EUA) contendo $10 \mathrm{ml}$ de meio de cultura Eagle modificado por Dulbecco's (DMEM) com penicilina $(100 \mu \mathrm{g} / \mathrm{ml})($ Gibco, EUA) e estreptomicina $(100 \mu \mathrm{g} / \mathrm{ml})($ Gibco, EUA), suplementado com 10\% de FBS (DMEM-c). Após a transferência das células, o tubo cônico que as continha foi centrifugado a 1.200 rpm, por 10 minutos, a 
$10^{\circ} \mathrm{C}$. Posteriormente, o sobrenadante foi descartado e as células constituintes do pellet foram ressuspendidas em $30 \mathrm{ml}$ de meio DMEM-c.

As células foram transferidas para a garrafa de cultura de $150 \mathrm{~cm}^{2}$ (Falcon ${ }^{\mathrm{TM}}$, Corning Inc., NY, EUA) e mantidas em estufa com controle de temperatura e pressão, $5 \%$ de $\mathrm{CO}_{2} \mathrm{e}$ fluxo de ar de 95\%, até atingirem $80 \%$ de confluência. O meio era trocado a cada 2-3 dias, sendo que a cada troca de meio de cultura a garrafa era lavada com $30 \mathrm{ml}$ de solução salina fosfatada tamponada (PBS), a fim de remover debris e células mortas presentes na cultura.

Assim que a cultura atingiu a confluência, o meio de cultura foi retirado, e a garrafa foi lavada com $30 \mathrm{ml}$ de PBS. Sequencialmente, $15 \mathrm{ml}$ de DMEM-c foram colocados na garrafa, e com o auxílio de um scraper esterilizado (Cell Scraper, Corning Glass Workers, NY, EUA), as células aderidas na superfície da garrafa foram destacadas. Após esse passo, o sobrenadante foi transferido para um tubo cônico e centrifugado a $1.200 \mathrm{rpm}$, por 10 minutos, a $10^{\circ} \mathrm{C}$. Então, o sobrenadante foi descartado e o pellet ressuspendido em $10 \mathrm{ml}$ de DMEM-C.

A contagem do número de células viáveis foi realizada em Câmara de Newbauer (BOECO Germany, Hamburg, Alemanha). Para tanto, 10 $\mu$ l da solução que contém as células

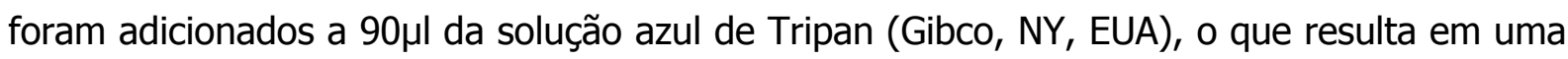
diluição na proporção 1:10.

Para os experimentos, as células foram transferidas para placas de cultura celular de 96 poços na densidade de $1 \times 10^{5}$ células/poço. As células foram mantidas em DMEM overnight em incubadora à temperatura de $37^{\circ} \mathrm{C}$, com $95 \%$ de ar e $5 \%$ de $\mathrm{CO}_{2}$.

\section{Preparo do Estímulo - Soluções de Papacárie}

Papacárie Duo ${ }^{\circledR}$ Gel (seringa de $1 \mathrm{ml}$ ) (Fórmula \& Ação, São Paulo, SP, Brasil) foi preparado na concentração de $50 \%$ por meio da mistura de $0,5 \mathrm{ml}$ de DMEM sem FBS e $0,5 \mathrm{ml}$ do gel. Então, $100 \mu \mathrm{l}$ da solução na concentração de $50 \%$ foi diluída em $900 \mu$ de 
DMEM obtendo a solução na concentração de $5 \%$ e $100 \mu$ desta foi diluída em $900 \mu l$ de DMEM obtendo a solução de Papacárie na concentração de 0,5\%.

O meio de cultura foi removido, os poços foram lavados com PBS 1x (salina fosfatada tamponada) e $200 \mu \mathrm{L}$ das soluções de 0,5, 5 e $50 \%$ de Papacárie Duo ${ }^{\circledR}$ foram adicionados em cada poço. Os experimentos foram realizados em triplicata por 24 e 36 horas. Após a incubação, os estímulos e sobrenadantes foram removidos e as placas foram armazenadas à $-80^{\circ} \mathrm{C}$.

\section{Liberação de Lactato Dehidrogenase - Ensaio LDH}

A citotoxicidade foi avaliada através da atividade de lactato dehidrogenase (LDH), uma enzima citosólica liberada no sobrenadante da célula após lise celular usando o ensaio de citotoxicidade não radioativo CytoTox $96^{\circledR}$ (Promega Corporation, Madison, WI, EUA). A absorvência foi medida em espectrofotômetro (Quanti, BioTek Instruments, Inc., Winooski, VT, EUA) a 490 nm. A concentração de LDH foi expressa em porcentagem com relação à concentração de LDH observada nas culturas mantidas sem estímulo (controle).

\section{Teste de Proliferação Celular - Ensaio Colorimétrico MTT}

A proliferação celular foi avaliada utilizando o ensaio MTT de acordo com as instruções do fabricante, como previamente descrito (Mosmann, 1983; Paula-Silva et al., 2010). 1 x $10^{5}$ OD-21 células / poço foram plaqueadas em placas de 96 poços de cultura de células e estimuladas com as soluções de Papacárie Duo ${ }^{\circledR}$ nas diferentes concentrações durante $36 \mathrm{~h}$.

Os estímulos foram removidos e $10 \mu \mathrm{L}$ de MTT [brometo de 3-(4,5-dimetiltiazol-2-il)2,5- difeniltetrazólio], Sigma-Aldrich CO., Número de catálogo M2128), suplementado com $150 \mathrm{~mL}$ de Roswell Park Memorial Institute (RPMI) 1640 (Gibco) foram adicionados às placas. Após $3 \mathrm{~h}$ de incubação, foram adicionados $40 \mu \mathrm{L}$ de SDS (dodecil sulfato de sódio) e 
a absorbância foi determinada utilizando um espectrofotômetro SpectraMax ${ }^{\circledR}$ Paradigm $^{\circledR}$ (Molecular Devices, LLC, Sunnyvale CA, EUA). Os dados obtidos foram analisados utilizando uma curva padrão que continha um número conhecido de células.

Avaliação da Expressão Gênica - Reação em Cadeia da Polimerase em Tempo Real (RT-PCR)

Para a avaliação da expressão gênica, foram realizadas sequencialmente a (i) extração do RNA total, (ii) a transcrição reversa do RNA e (iii) a reação de RT-PCR em tempo real, como descrito a seguir.

\section{Extração do RNA total}

Para obtenção do RNA total foi realizado protocolo de extração à base de tiocianato de guanina pelo método de colunas (RNeasy ${ }^{\circledR}$ Mini, Qiagen Inc., Valencia, EUA). Para tanto, $300 \mu$ le solução tampão RLT (Qiagen) foram colocados em cada poço visando lisar as amostras. O tampão foi transferido para um eppendorf e foram adicionados 300 $\mu$ le álcool $70 \%$, previamente preparado com água livre de RNAse (Ambion ${ }^{\mathrm{TM}}$, Life Technologies, USA) com intuito de permitir a ligação do RNA à membrana presente na coluna de purificação. Os $600 \mu \mathrm{l}$ foram transferidos para a coluna contendo tubo coletor acoplado e os tubos foram centrifugados a $10.000 \mathrm{rpm}$ por 15 segundos em microcentrífuga (Fanem ${ }^{\circledR}$ centrífuga micro mod. 243; São Paulo, Brasil). Os filtrados foram coletados, acondicionados em microtubos de $1,5 \mathrm{ml}$ e mantidos à temperatura de $-20^{\circ} \mathrm{C}$.

Na sequência, 350ul de solução tampão RW1 foram colocados na coluna de cada amostra, com a sequente centrifugação a $10.000 \mathrm{rpm}$ por 15 segundos. Após esta

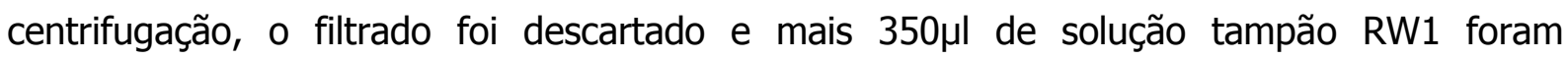
colocados em cada coluna. Nova centrifugação foi realizada nas mesmas condições já citadas. 
Sequencialmente, utilizou-se $500 \mu$ de solução tampão RPE contendo etanol, com a posterior centrifugação a $10.000 \mathrm{rpm}$ por 15 segundos. Novamente, $500 \mu l$ de tampão RPE com etanol foram adicionados à coluna e os tubos centrifugados a $10.000 \mathrm{rpm}$, por 2 minutos. A fim de eliminar qualquer remanescente da solução tampão de RPE com etanol utilizado anteriormente, o tubo coletor foi descartado, a coluna montada em um novo tubo coletor e centrifugada a 10.000 rpm por 1 minuto.

Para obtenção do RNA total, o tubo coletor foi descartado e as colunas acopladas a microtubos de 1,5ml. O RNA presente na membrana foi, então, eluído em $40 \mu \mathrm{l}$ de água livre de RNAse.

A pureza e a estimativa da quantidade de ácidos nucleicos foi realizada utilizando a espectrofotometria em NanoDrop 2000 (Thermo Fisher Scientific Inc., Wilmington, USA) e software NanoDrop 2000/2000c (Thermo Fisher Scientific Inc., Wilmington, USA), nos comprimentos de onda de 230, 260 e $280 \mathrm{~nm}$.

\section{Transcrição Reversa (RT) - Síntese de RNA Complementar (CDNA)}

O cDNA foi sintetizado por meio de reação de transcrição reversa a partir de uma massa de $1 \mu \mathrm{g}$ de RNA total. Para tanto, foi utilizado o kit High Capacity cDNA Reverse Transcription (Applied Biosystems, Foster City, EUA). Em tubos de 0,2ml (Axygen Scientific, Inc.) foram adicionados ao RNA total $2,0 \mu$ l de solução tampão $10 x, 0,8 \mu l$ de dNTP mixture

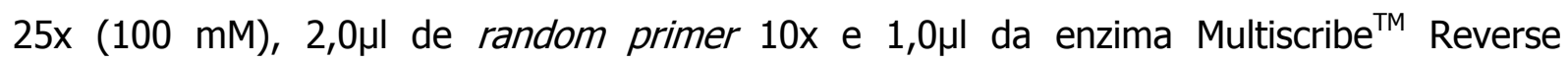

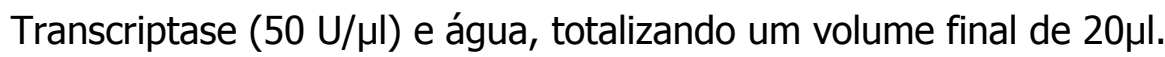

As amostras foram incubadas em termociclador (Veriti ${ }^{\circledR}$ Thermal Cycler, Applied Biosystems, EUA) por 10 minutos a $25^{\circ} \mathrm{C}$ para ligação do primer ao RNA, seguida de incubação a $37^{\circ} \mathrm{C}$ por 2 horas para transcrição reversa e incubação sequente a $85^{\circ} \mathrm{C}$ por 5 minutos para inativação da enzima transcriptase reversa e conclusão do processo. O cDNA resultante foi armazenado a temperatura de $-20^{\circ} \mathrm{C}$ até o momento do uso. 


\section{Amplificação e Análise da Expressão Gênica em Tempo Real - Reação em Cadeia da}

\section{polimerase}

Para as reações de qRT-PCR foi utilizado o sistema TaqMan ${ }^{\circledR}$. Para tanto, alíquotas de $2 \mu \mathrm{l}$ de cDNA (o equivalente a 50ng de cDNA/poço) foram adicionados a $10 \mu \mathrm{l}$ de $\operatorname{TaqMan}^{\circledR}$ Fast Advanced Master Mix (Applyed Biosystems, Life technologies, USA), $1 \mu$ le TaqMan ${ }^{\circledR}$ Gene Expression Assay 20x (AB Applyed Biosystems, Life technologies, USA) (par de primers e sonda) e água livre de RNAse, totalizando um volume de $20 \mu \mathrm{l} /$ poço. Os pares de primers e sondas para Ibsp (Mm00492555_m1), Runx2 (Mm00501584_m1), Spp1 (Mm00436767_m1), Gapdh (Mm99999915_g1) e Actb (Mm04394036_g1) foram obtidos comercialmente e, portanto, suas sequências não estão disponíveis comercialmente. As concentrações finais dos primers foram de 900 nM cada e da sonda MGB (Minor Groove Binding) de 250 nM. Os genes para a enzima gliceraldeído-3-fosfato desidrogenase (Gapdh) e proteína ( $\beta$ )-actina (Actb) foram utilizados como referências, sendo o fluoróforo 6-FAM utilizado como repórter e liberado após clivagem por meio da polimerase com atividade exonuclease 5 '.

As soluções, então, foram distribuídas em placas de 96 poços (MicroAmp ${ }^{\circledR}$ Applied Biosystems) sendo o volume total de cada poço de $20 \mu \mathrm{l}$. As reações de qRT-PCR foram realizadas em duplicata utilizando o aparelho StepOne Plus ${ }^{\circledR}$ (StepOne Plus ${ }^{\circledR}$ Real-Time PCR System, Applied Biosystems). A amplificação da cadeia de cDNA foi iniciada com a ativação da polimerase AmpliTaq Gold Enzyme à temperatura de $95^{\circ} \mathrm{C}$ por 2 minutos, seguida por 40 ciclos a $95^{\circ} \mathrm{C}$ por 1 segundo, para desnaturação do DNA, e $60^{\circ} \mathrm{C}$ por 20 segundos para anelamento dos primers e polimerização.

Os resultados foram analisados com base no valor do ciclo limiar ( $\mathrm{Ct}$; cycle threshold), valor correspondente ao número de ciclo no qual a amplificação das amostras atingiu um limiar, determinado entre o grau de fluorescência dos controles negativos e a fase de amplificação exponencial das amostras que permitiu a análise quantitativa da 
expressão do gene avaliado. Água livre de RNAse foi utilizada como controle negativo e foi submetida à reação com cada par das sequências dos primers e sondas analisados.

O Ct determinado para cada amostra foi subtraído do Ct resultante da média geométrica dos genes de referência (Gapdh e Actb) da mesma amostra. Dessa forma, obteve-se o valor do $\Delta$ Ct. Para cada gene, a expressão relativa foi calculada a partir da diferença entre o valor do $\Delta \mathrm{Ct}$ de cada amostra e o $\Delta \mathrm{Ct}$ do controle ( $\Delta \Delta \mathrm{Ct})$, tendo como base a equação: $2^{-\Delta \Delta c t}$.

\section{Análise Estatística}

Os grupos foram comparados utilizando a análise de variância de uma via (ANOVA) seguida pelo pós teste de Tukey $(a=0,05)$. Os dados foram analisados por meio do software Graphpad Prism 6 (Graphpad Software Inc., La Jolla, USA).

\section{RESULTADOS}

\section{Citotoxicidade e Proliferação Celular}

O Papacárie Duo ${ }^{\circledR}$ à $5 \%$ foi citotóxico para células da polpa dental $(\mathrm{p}<0,05)$, porém à $0,5 \%$ não foi citotóxico $(p>0,05)$ comparado ao meio de cultura somente (Figura $1 \mathrm{~A})$. Papacárie Duo $^{\circledR}$ à $5 \%$ inibiu a proliferação celular $(p<0,05)$ e à $0,5 \%$ não exerceu nenhum efeito comparado ao meio de cultura $(p>0,05)$ (Figura 1B). 
A

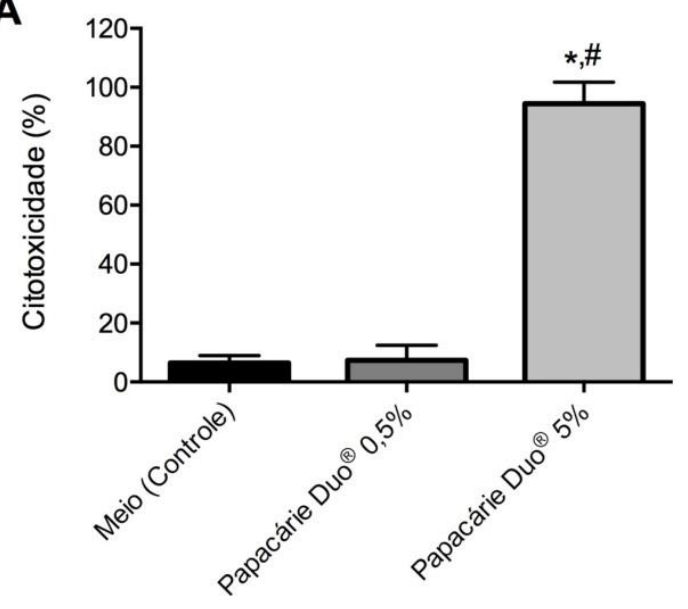

B

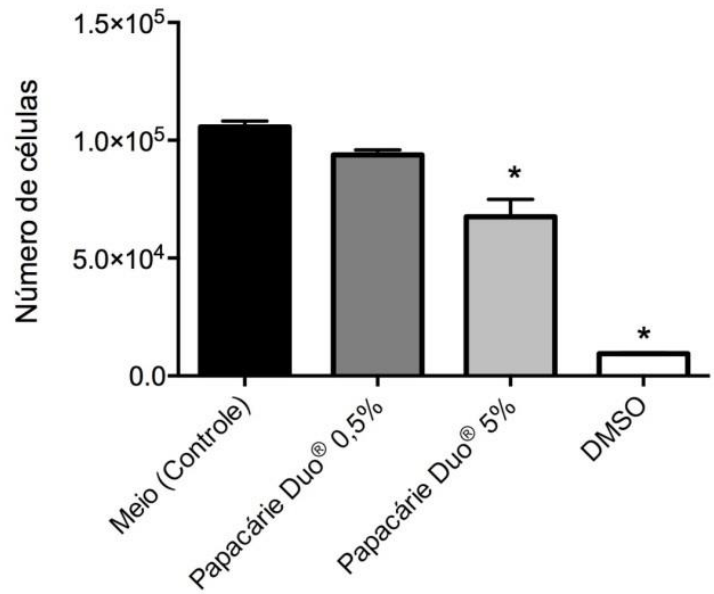

Figura 1. Efeito do Papacárie Duo ${ }^{\circledR}$ na citotoxicidade de células indiferenciadas da polpa dental (OD21) pelo Ensaio LDH após 24 horas (A) e proliferação celular pelo Ensaio de MTT após 36 horas (B) * $p$ $<0,05$ comparada com meio de cultura; \#p<0,05 comparada com Papacárie Duo ${ }^{\circledR}$ à 0,5\%.

\section{Diferenciação Celular}

O Papacárie Duo ${ }^{\circledR}$ inibiu a expressão de $\operatorname{Runx2}(p<0,05)$ e Ibsp $(p<0,05)$ independente da concentração utilizada. Por outro lado, o Papacárie Duo ${ }^{\circledR}$ estimulou a expressão de $\operatorname{Spp1}(p>0,05)$ e esta foi maior com Papacárie Duo ${ }^{\circledR}$ à $5 \%(p<0,05)$ comparado à $0,5 \%(p<0,05)$ (Figura 2). 
A

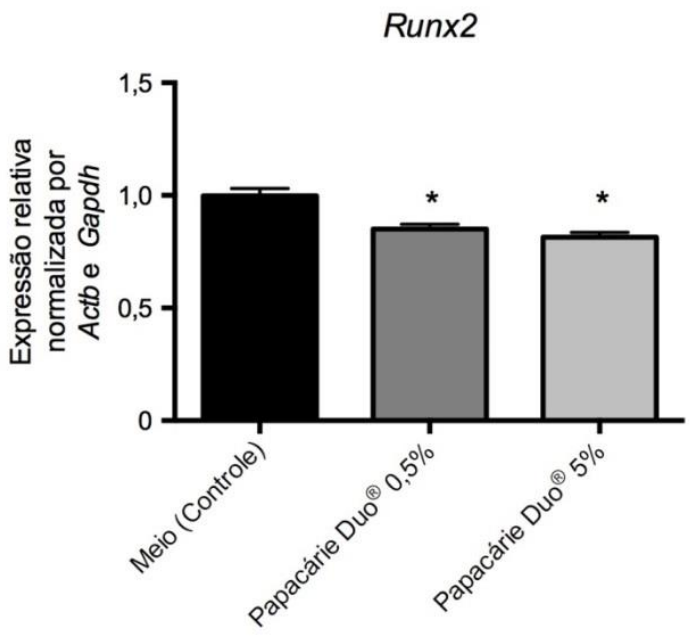

B

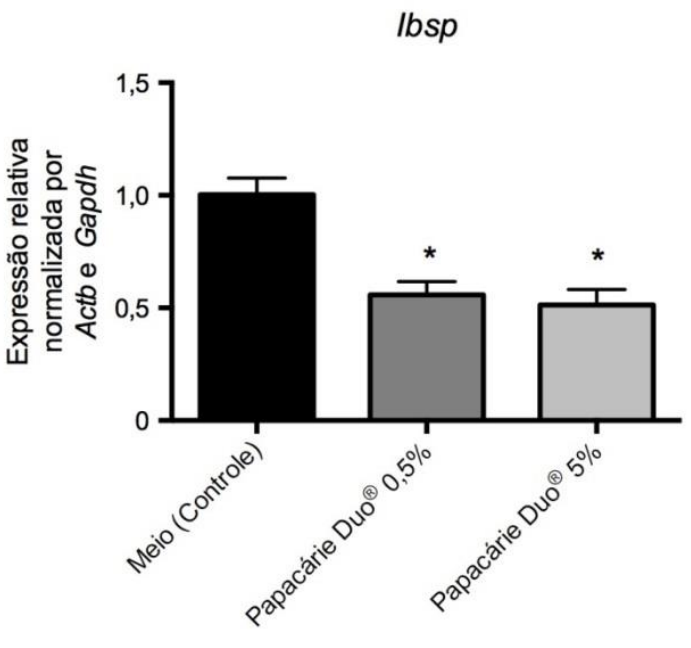

C

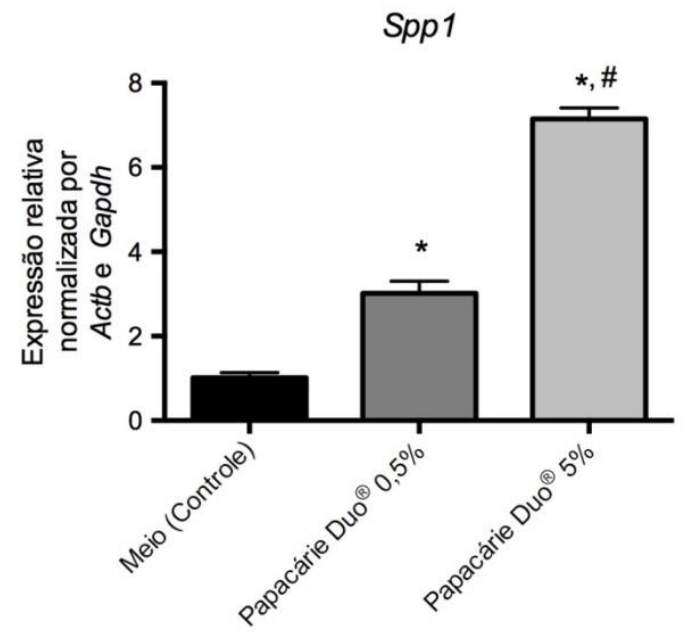

Figura 2. Expressão de Runx2 (A), Ibsp (B) and $\operatorname{Spp1}(\mathrm{C})$ após estimulção com Papacárie Duo ${ }^{\circledR}$ após 24 horas. ${ }^{*} p<0,05$ comparado com meio de cultura somente; $\# p<0,05$ comparado com Papacárie Duo ${ }^{\circledR}$ à $0,5 \%$. 


\section{DISCUSSÃO}

Os dados deste estudo demonstraram que o Papacárie Duo ${ }^{\circledR}$ à $0,5 \%$ não apresentou citotoxicidade, diferentemente da concentração de 5\%, que foi citotóxica. A citotoxicidade do Papacárie também foi testada no trabalho de Martins et al. (Martins et al., 2009), porém com fibroblastos, células abundantes na região central do tecido pulpar, sem diferença em relação ao grupo controle. Embora a concentração de $0,5 \%$ não tenha influenciado a proliferação celular, a baixa proliferação encontrada com relação ao Papacárie à $5 \%$ pode ser devido à morte celular, detectada pelo ensaio LDH.

Considerando então uma possível toxicidade às células da polpa dentária, como indicado pelos resultados referentes à concentração de $5 \%$, a espessura de dentina remanescente após o preparo cavitário é um fator de alta relevância. A espessura e as características morfológicas da dentina favorecem a difusão transdentinária de componentes químicos dos materiais, sendo que as reações pulpares mais graves ocorrem quando o remanescente dentinário é menor (Huang et al., 2010). Portanto, futuros estudos clínicos devem ser realizados com o objetivo de investigar se a indicação do material deve ser em função da profundidade cavitária.

No que se refere à diferenciação celular, o Papacárie Duo ${ }^{\circledR}$, em ambas concentrações pesquisadas, inibiu a expressão dos genes Runx2 e Ibsp. O Runx2 coordena múltiplas vias de sinalização relacionadas tanto à diferenciação osteoblástica (Komori, 2010), quanto à odontoblástica (D'Souza et al., 1999; ; Yang et al., 2014; Daltoé et al., 2016). No processo de diferenciação de odontoblastos, é expresso em células odontoblast-like e em célulastronco da polpa dental na região de deposição de dentina reparadora, o que torna esse fator transcripcional um promotor da diferenciação de células-tronco pulpares, para que assim essas células sejam capazes de formar dentina reparadora (Han et al., 2014; Daltoé et al., 2016). Por outro lado, o gene Ibsp, que codifica uma glicoproteína fosforilada, expressa principalmente nos tecidos conjuntivos mineralizados, desempenha papéis múltiplos e 
distintos no desenvolvimento, no volume e na mineralização do tecido ósseo e dentinário. A indução desse gene coincide com a formação inicial de matriz mineralizada, e a concentração máxima de indução é obtida durante a formação óssea (Ganss et al., 1999; Ogata, 2008). Dessa forma, considerando os papeis desempenhados na diferenciação celular por ambos os genes, Runx2 e Ibsp, tem-se que a inibição de suas expressões gênicas relativas é capaz, portanto, de causar efeito inibitório na diferenciação das células OD-21.

Diferentemente desses resultados encontrados sobre os genes Runx2 e Ibsp, 0 Papacárie Duo ${ }^{\circledR}$ induziu a expressão de $\operatorname{Spp1}$, um gene que codifica a proteína osteopontina (OPN), uma glicoproteína altamente fosforilada, componente da matriz extracelular mineralizada do osso e importante para eventos inflamatórios e de mineralização, por ser capaz de regular diversos processos fisiológicos e patológicos, incluindo cicatrização de feridas, remodelação óssea, tumorigênese, inflamação e respostas imunológicas (Pagel et al., 2014). Trabalhos recentes mostraram que células imunocompetentes, como macrófagos e células dendríticas, secretam a OPN, que é depositada na interface dentina-pré-dentina, o que ocorre antes da diferenciação de células odontoblast-like, sugerindo que a OPN possui um papel na diferenciação dessas células (Saito et al., 2011). Esta, uma vez depositada na interface polpa-dentina, induz então a formação de dentina terciária, assim como de colágeno tipo I, sendo este essencial para o processo de mineralização, devido à formação de nova matriz mineralizada (Saito et al., 2016). Assim, novas pesquisas devem ser realizadas, uma vez que a expressão de $\operatorname{Spp1}$, gene que codifica a OPN, está relacionada não somente a eventos de mineralização, mas também a eventos inflamatórios (Scatena et al., 2007; Chatakun et al., 2014). Do mesmo modo, a repercussão clínica do efeito indutor observado neste estudo pelo Papacárie merece investigação em estudos futuros.

Sem dúvida, a remoção químico-mecânica da cárie é considerada um dos métodos mais convenientes e conservadores (Bohari et al., 2012) e deve ser estimulada. Esse método tem sido modificado no decorrer dos anos, por exemplo, através de alterações da fórmula do 
gel Carisolv ${ }^{\mathrm{TM}}$ e também pela introdução de novos agentes a base de enzimas (Papacárie, Biosolv) (Hamama et al., 2015). Muito tem se pesquisado sobre os efeitos dos agentes de remoção químico-mecânica do tecido cariado em relação à sua eficácia clínica, nível de dor e sucesso a longo prazo, mas poucos são os estudos sobre os efeitos nas células. Esta foi justamente a abordagem deste trabalho, em que pesquisamos o efeito celular do Papacárie Duo ${ }^{\circledR}$.

Tendo em vista nossos resultados, acreditamos que o principal componente do Papacárie $D$ Duo ${ }^{\circledR}$, a papaína, uma enzima proteolítica, auxilia na cicatrização de feridas no tecido conjuntivo e pele, porém sem efeito em eventos associados à regeneração/reparação por células da polpa dentária. Entretanto, o mesmo não é observado para a OPN, que é capaz de recrutar macrófagos, ou seja, está envolvida na regulação da resposta imunoinflamatória.

Assim, demonstramos que o Papacárie Duo ${ }^{\circledR}$ pode ser citotóxico às células da polpa dentária dependendo da concentração empregada, porém não influencia a proliferação celular. Apresenta, ainda, um efeito inibitório na diferenciação de células da polpa. 

3. Capitulo 2 



\section{Papacárie duo ${ }^{\circledast}$ Induz a ativação de macrófagos e expressão de mediadores INFLAMATÓRIOS}

Na doença cárie, o equilíbrio pulpar pode ser interrompido pela inflamação (Farges et al., 2015). Uma vez que as bactérias desmineralizam o esmalte por meio de seus produtos e atingem a dentina, elas podem se espalhar através dos túbulos dentinários e atingir a polpa dental. Dessa forma, o lipopolissacarídeo (LPS), presente na parede celular de bactérias Gram-negativas, pode penetrar na polpa e estimular uma resposta inflamatória a partir de uma variedade de células residentes nos tecidos, dentre elas, os macrófagos (Cooper et al., 2010).

Durante um processo inflamatório no tecido conjuntivo, os macrófagos, que são células que participam da reação de defesa do organismo, são recrutados para executarem o processo de fagocitose e liberação de mediadores químicos. Esses mediadores, por sua vez, são necessários para o aporte de células de defesa, para o reparo tecidual, mas quando produzidos em desordenadamente são responsáveis pela destruição tecidual local (Okiji et al., 1992; Murray e Wynn, 2011).

Quando estimulados por fatores exógenos, como LPS, ou por fatores endógenos, como o interferon gama (IFNr) produzido por linfócitos T, os macrófagos têm suas funções bastante aumentadas, tornando-se células ativadas. Um macrófago ativado aumenta de tamanho e volume celular, adere fortemente às superfícies e produz grandes quantidades de mediadores biológicos pró e anti-inflamatórios (Metzger, 2000; Murray e Wynn, 2011).

Sabendo-se da íntima relação entre a dentina e o tecido pulpar, é importante que os materiais odontológicos sejam biocompatíveis e, idealmente, apresentem propriedades antiinflamatórias. Paralelamente, a profundidade cavitária também apresenta relevância. Há materiais que podem ser biocompatíveis com complexo dentino-pulpar quando aplicados sobre cavidades rasas e médias, onde a permeabilidade da dentina é menor; por outro lado, 
esses mesmos materiais podem apresentar efeitos indesejáveis ao tecido pulpar, quando aplicados em cavidades mais profundas, pois a espessura e as características morfológicas da dentina remanescente favorecem a difusão transdentinária dos componentes químicos dos materiais, os quais podem ser tóxicos ao tecido pulpar ou ainda interferir negativamente no processo de reparo (Marshall et al., 1997; Costa et al., 2011).

O Papacárie Duo ${ }^{\circledR}$ é um gel utilizado para remoção químico-mecânica da cárie, constituído basicamente por papaína, que possui propriedades bactericidas, bacteriostáticas e anti-inflamatórias (Bussadori et al., 2005). Portanto, o objetivo desse estudo foi verificar se o Papacárie Duo ${ }^{\circledR}$ apresenta capacidade imunomodulatória em macrófagos, pré-estimulados ou não com LPS.

\section{MATERIAIS E MÉTODOS}

\section{Cultura de macrófagos J774.1}

A linhagem de macrófagos 3774.1 de camundongos, foi previamente obtida da Coleção Americana de cultura de células (ATCC, Rockville, MD, USA). As células foram cultivadas em meio DMEM suplementado com $10 \%$ de soro fetal bovino (DMEM-c) e $1 \%$ Penicilina/Estreptomicina (Gibco). Após formação de uma monocamada, as células foram coletadas utilizados raspadores de plástico e centrifugadas à $1.500 \mathrm{rpm}$ por 10 min à $10^{\circ} \mathrm{C}$ (Beckman). Após a centrifugação, os sobrenadantes foram descartados e $10 \mathrm{~mL}$ de DMEM-c foi adicionado a cada tubo que continha as células. O número total de células foi contado e a viabilidade foi determinada em uma câmara de Neubauer (BOECO Germany, Hamburg, Germany) utilizando azul de Trypan (Gibco, Grand Island, NY). As células foram plaqueadas em placas de cultura de 96 poços (Cell Wells - 25,820, Corning Glass Works) em uma densidade de $1 \times 10^{5}$ células/poço e incubadas overnight em DMEM-c a $37^{\circ} \mathrm{C}$ e $5 \% \mathrm{CO}_{2}$. 


\section{Pré estimulação com LPS}

As células foram pré-estimuladas com LPS $(0,2 \mathrm{mg} / \mathrm{mL})$ (Escherichia coli LPS, SigmaAldrich, St. Louis, MO, EUA). Duas horas depois da estimulação com LPS, o Papacárie Duo ${ }^{\circledR}$ foi adicionado em diferentes concentrações (0,5 e 5\%). As células expostas apenas ao LPS foram usadas como controle positivo.

Preparo do estímulo - Soluções de Papacárie Duoß

O Papacárie Duo ${ }^{\circledR}$ Gel (seringa de 1ml) (Fórmula \& Ação, São Paulo, SP, Brasil) foi preparado na concentração de $50 \%$, por meio da mistura de $0,5 \mathrm{ml}$ de DMEM sem FBS e 0,5ml do gel. Então, $100 \mu$ da solução na concentração de $50 \%$ foi diluída em $900 \mu l$ de DMEM obtendo a solução na concentração de $5 \%$ e $100 \mu$ desta foi diluída em $900 \mu l$ de DMEM obtendo a solução de Papacárie Duo ${ }^{\circledR}$ na concentração de 0,5\%.

O meio de cultura foi removido, os poços foram lavados com PBS 1x e $200 \mu \mathrm{L}$ das soluções de $0,5 \%$ e $5 \%$ de Papacárie Duo $^{\circledR}$ foram adicionados em cada poço. Os experimentos foram realizados em triplicata por 24 e 36 horas. Após a incubação, os sobrenadantes e as placas foram armazenados à $-80^{\circ} \mathrm{C}$.

\section{Liberação de Lactato Desidrogenase - Ensaio LDH}

A citotoxicidade foi avaliada através da mensuração da concentração de lactato desidrogenase (LDH), uma enzima citosólica liberada no sobrenadante da cultura após lise celular usando o ensaio de citotoxicidade não radioativo (CytoTox 96 ${ }^{\circledR}$; Promega Corporation, Madison, WI, EUA). A absorvência foi medida com um espectrofotômetro (Quanti, BioTek Instruments, Inc., Winooski, VT, EUA) no comprimento de onda de $490 \mathrm{~nm}$. A concentração de LDH foi expressa em porcentagem com relação à concentração de LDH observada nas culturas mantidas sem estímulo (controle). 
Teste de Proliferação Celular - Ensaio Colorimétrico MTT

A proliferação celular foi avaliada utilizando o ensaio MTT de acordo com as instruções do fabricante, como previamente descrito (Mosmann, 1983; Paula-Silva et al., 2010). $1 \times 10^{5}$ células / poço foram plaqueadas em placas de 96 poços de cultura de células e estimuladas com as soluções de Papacárie Duo ${ }^{\circledR}$ nas diferentes concentrações durante 36 h.

Os estímulos foram removidos e $10 \mu \mathrm{L}$ de MTT (brometo de 3- (4,5-dymethylthiazol2-il) -2,5-diphenyltetrazoluim, Sigma-Aldrich CO., Número de catálogo M2128), suplementado com $150 \mathrm{~mL}$ de Roswell Park Memorial Institute (RPMI) 1640 (Gibco) foi adicionado às placas. Após $3 \mathrm{~h}$ de incubação, foi adicionado $40 \mu \mathrm{L}$ de SDS (dodecil sulfato de sódio) e tampão de viabilidade celular foi determinada utilizando um espectrofotômetro SpectraMax ${ }^{\circledR}$ Paradigm $^{\circledR}$ (Molecular Devices, LLC, Sunnyvale CA, EUA). Os dados obtidos foram analisados utilizando uma curva padrão que continha um número conhecido de células.

Extração de RNA, Transcrição reversa, e Reação em Cadeia da Polimerase em Tempo Real (RT-PCR)

Para avaliação da ativação celular, as concentrações de RNA mensageiro para Ptgs2 (Mm00478374_m1), I/10 (Mm01288386_m1), Tnf (Mm00443258_m1), Mmp9 (Mm00442991_m1), Gapdh (Mm99999915_g) e Actb (Mm04394036_g1) foram avaliadas por qRT-PCR. Para isso, o RNA total foi extraído utilizando o Mini kit RNeasy ${ }^{\circledR}$ (Qiagen Inc., Valencia, USA) e estimado utilizando um espectrofotômetro NanoDrop 2000 (Thermo Fisher Scientific Inc., Wilmington, USA). Sequencialmente, o cDNA foi sintetizado por meio de reação de transcrição reversa a partir de uma massa de $1 \mu \mathrm{g}$ de RNA total utilizando o kit High Capacity cDNA Reverse Transcription (Applied Biosystems, Foster City, USA) em um termociclador (Veriti ${ }^{\circledR}$ Thermal Cycler, Applied Biosystems, USA). As reações de PCR foram 
realizadas em duplicata utilizando o sistema $\operatorname{TaqMan}^{\circledR}$ em um aparelho StepOne Plus ${ }^{\circledR}$ (StepOne Plus $\circledR$ Real-Time PCR System, Applied Biosystems). As amplificações foram realizadas como segue: $95^{\circ} \mathrm{C}$ por $20 \mathrm{~s}$, seguida por 40 ciclos à $95^{\circ} \mathrm{C}$ por $1 \mathrm{~s}$, e $60^{\circ} \mathrm{C}$ por 20 s. Todos os protocolos foram realizados de acordo com as instruções do fabricante. Os pares de primers e sondas foram obtidos comercialmente e, portanto, suas sequências não estão disponíveis. Os genes para a enzima gliceraldeído-3-fosfato desidrogenase (Gapdh) e proteína $\beta$-actina $(A c t b)$ foram utilizados como referências. Os resultados foram analisados com base no valor do ciclo limiar (Ct; cycle threshold). Para cada gene, a expressão relativa foi calculada pelo método $\Delta \Delta \mathrm{Ct}$.

\section{Análise Estatística}

Os grupos foram comparados utilizando a análise de variância de uma via (ANOVA) seguida pelo pós teste de Tukey $(a=0,05)$. Os dados foram analisados por meio do software Graphpad Prism 6 (Graphpad Software Inc., La Jolla, USA).

\section{RESULTADOS}

Citotoxicidade e proliferação celular induzidas pelo Papacárie Duoß

O Papacárie Duo $^{\circledR}$ à $5 \%$ foi citotóxico para macrófagos $(p<0,05)$. Porém, na concentração à $0,5 \%$, não apresentou citotoxicidade $(p>0,05)$, quando comparado ao meio de cultura (Figura 1A). O Papacárie Duo ${ }^{\circledR}$ não influenciou a proliferação celular em nenhuma das concentrações $(p>0,05)$ (Figura 1B). 
A
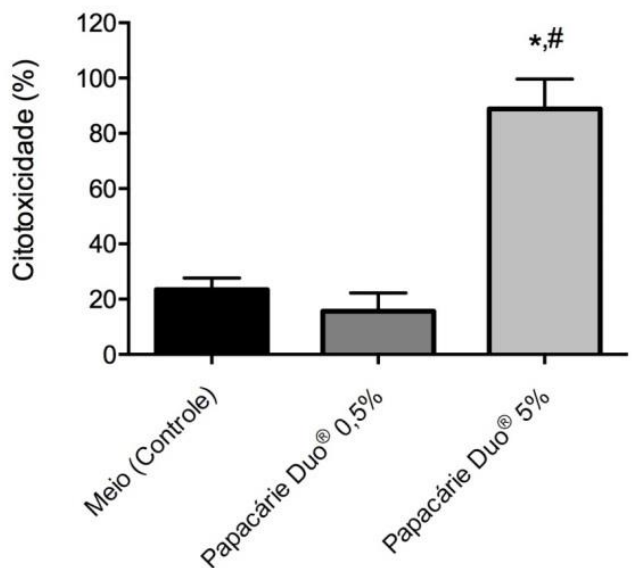

B

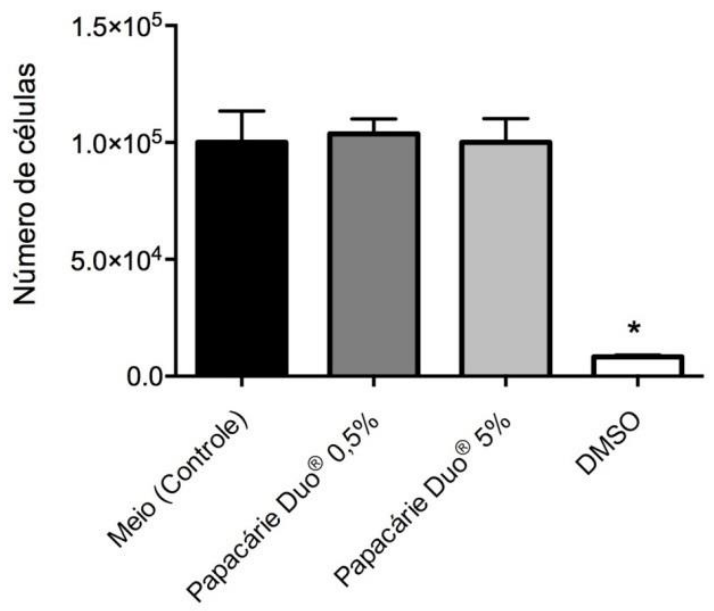

Figura 1. Citotoxicidade do Papacárie Duo ${ }^{\circledR}$ em macrófagos (J774.1) pelo Ensaio LDH após 24h (A) e proliferação celular pelo método MTT após $36 \mathrm{~h}(\mathbf{B}) .{ }^{*} p<0,05$ comparado ao meio de cultura somente; $\# p<0,05$ comparado com Papacárie Duo ${ }^{\circledR}$ à $0,5 \%$.

Na presença de LPS, houve inibição da proliferação de macrófagos, quando as células foram estimuladas ou não com Papacárie Duo ${ }^{\circledR}(p<0,05)$, sem apresentar citotoxicidade $(p>0,05)$ (Figura 2). 

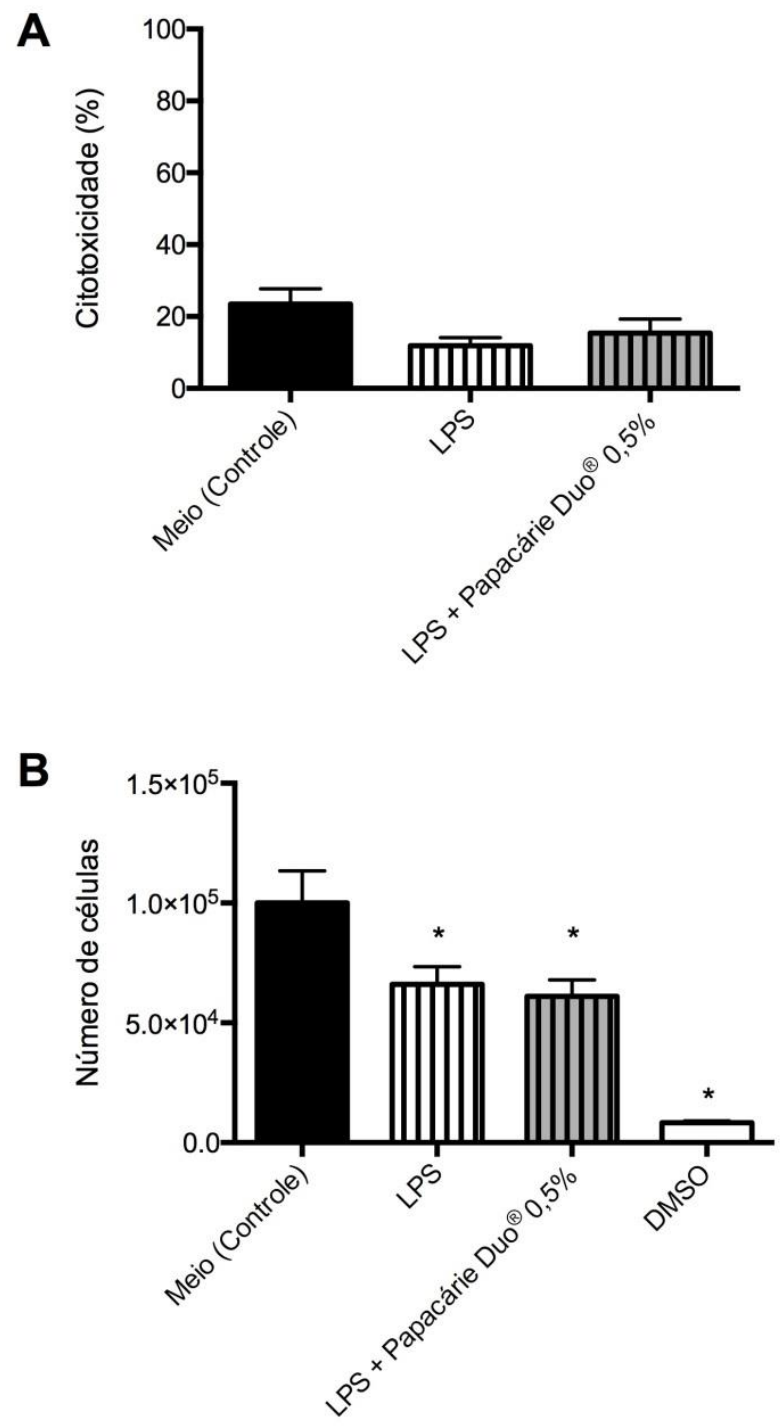

Figura 2. Efeito do Papacárie Duo ${ }^{\circledR} 0,5 \%$ na presença ou não de LPS na citotoxicidade de macrófagos (J774.1) pelo Ensaio LDH após $24 \mathrm{~h}$ (A) e na proliferação celular pelo Ensaio de MTT após $36 \mathrm{~h}$ (B). ${ }^{*} p<0,05$ comparado ao meio de cultura somente.

Ativação do macrófago pelo Papacárie Duo ${ }^{\circledR}$ na presença ou não do LPS

O Papacárie Duo® à $0,5 \%$ não alterou a expressão de $\operatorname{Tnf}(p>0,05)$. O LPS estimulou a expressão de Tnf comparado ao meio de cultura $(p<0,05)$. O Papacárie Duo ${ }^{\circledR}$ à 0,5\%, na presença de LPS, não alterou a expressão de $\operatorname{Tnf}(p>0,05 ;$ Figura $3 \mathrm{~A})$.

O Papacárie Duo ${ }^{\circledR}$ à $0,5 \%$, na presença ou não de LPS, não alterou a expressão de $\operatorname{Mmp9}(p>0,05 ;$ Figura 3B). 
O Papacárie Duo ${ }^{\circledR}$ à $0,5 \%$ inibiu a expressão de $\operatorname{Ptgs} 2(p<0,05)$, diferentemente do LPS que induziu a expressão de Ptgs2 $(p<0,05)$. Interessantemente, o Papacárie Duo ${ }^{\circledR}$ à 0,5\% aumentou a expressão de Ptgs2 induzida pelo LPS ( $p<0,05$; Figura 3C).

O Papacárie Duo ${ }^{\circledR}$ à $0,5 \%$ estimulou a expressão de $I / 10(p<0,05)$, na presença ou ausência de LPS (Figura 3D).

A

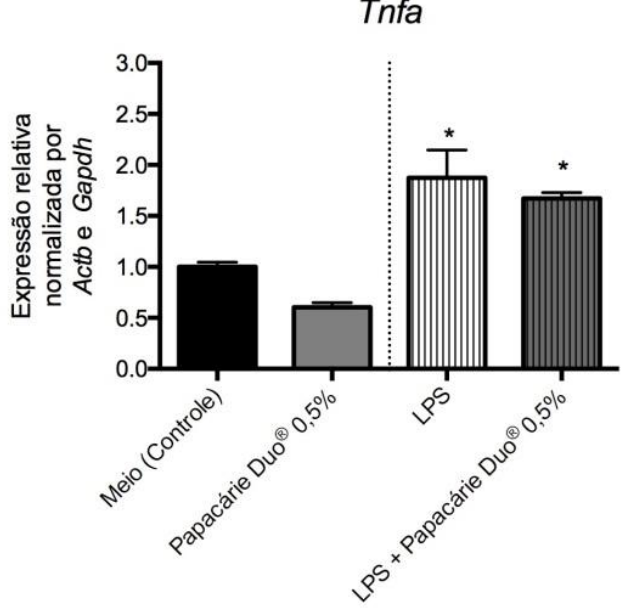

C

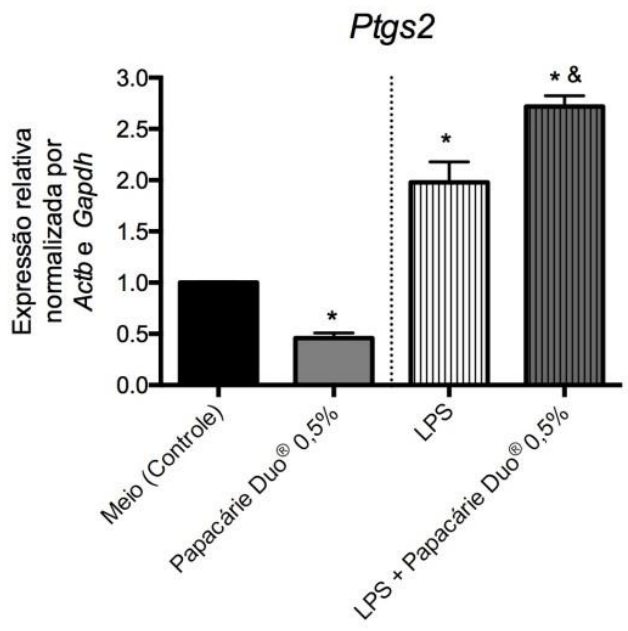

B

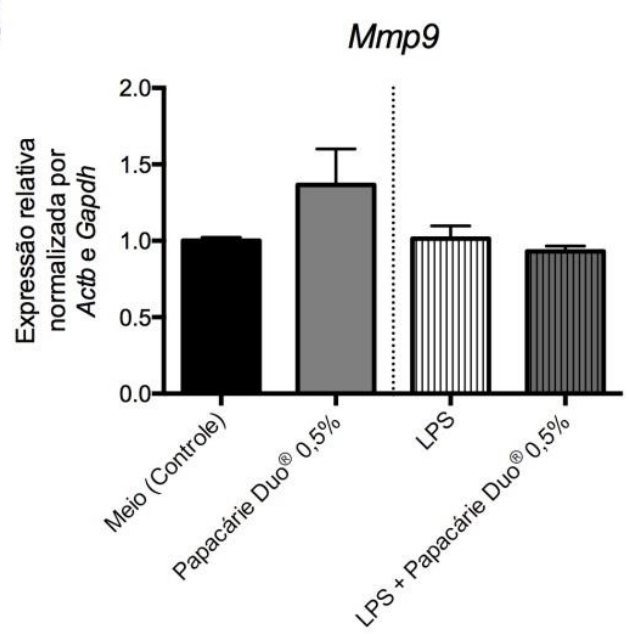

D

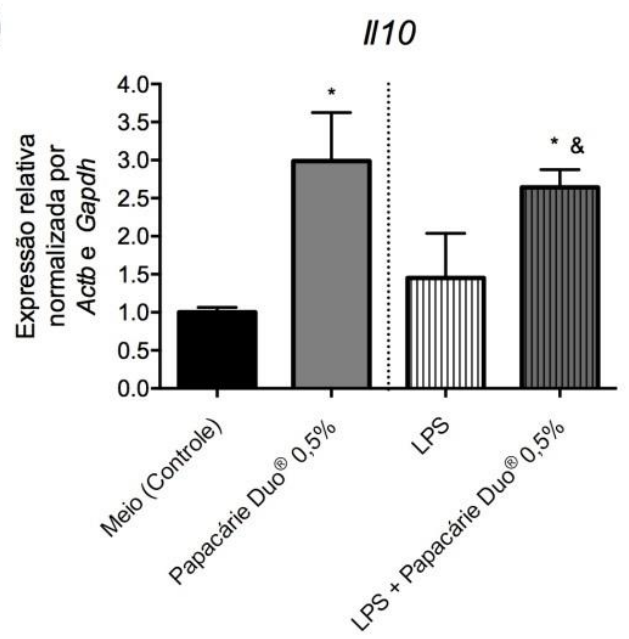

Figura 3. Efeito do Papacárie Duo ${ }^{\circledR} 0,5 \%$ na presença ou não de LPS na expressão gênica de Tnf (A), Mmp9 (B), Ptgs2 (C) e I/10 (D), após 24 horas da estimulação, pelo RT-PCR. ${ }^{*} p<0,05$ comparado ao meio de cultura somente; ${ }^{\&} p<0,05$ comparado com LPS. 


\section{DISCUSSÃO}

Os teste de citotoxicidade são bastante utilizados (de Azevedo et al., 2003; Cavalcanti et al., 2006) visando simular in vitro os processos que ocorrem in vivo, e portanto a resposta de um tipo celular específico a determinados produtos pode ser investigada neste tipo de abordagem experimental (Schmalz, 1994).

Os dados deste estudo mostraram que o Papacárie Duo ${ }^{\circledR}$ à 0,5\% não apresentou citotoxicidade, diferentemente da concentração de 5\%, que foi citotóxica. Devido a elevada citotoxicidade de Papacárie Duo ${ }^{\circledR}$ à $5 \%$, essa concentração não foi considerada adequada para uso em experimentos subsequentes. No estudo de Garcia-Contreras et al. (GarciaContreras et al., 2014), que investigaram a citotoxicidade em diferentes tipos celulares, também foi encontrado efeito citotóxico de Papacárie Duo ${ }^{\circledR}$, porém em fibroblastos do ligamento periodontal, células epiteliais e cancerosas da mucosa oral. Por outro lado, menor efeito citotóxico foi encontrado em células da polpa humana e em fibroblastos gengivais humanos. A ausência de citotoxicidade do Papacárie Duo ${ }^{\circledR}$ também foi demonstrada no estudo de Martins et al. (Martins et al., 2009), porém com fibroblastos, células abundantes na região central do tecido pulpar.

É válido ressaltar que a citotoxicidade de um material depende também da espessura da dentina remanescente e de sua permeabilidade (Murray et al., 2000; Duque et al., 2006; Costa et al., 2011). Assim, cavidades mais profundas requerem maiores cuidados quanto ao uso de alguns materiais odontológicos, e o manuseio incorreto destes materiais pode resultar em significantes danos aos tecidos e polpa.

Ainda no trabalho de García-Contreras et al. (Garcia-Contreras et al., 2014), os autores investigaram a produção do mediador lipídico pró-inflamatório Prostaglandina $E_{2}$ $\left(\mathrm{PGE}_{2}\right)$ e encontraram aumento da sua produção em fibroblastos gengivais, além dessa produção de $\mathrm{PGE}_{2}$ ter sido sinergicamente aumentada na presença de IL-1ß. Em nosso 
estudo, encontramos aumento na expressão gênica de Ptgs2. O gene Ptgs2 codifica a enzima ciclo-oxigenase-2 (COX-2), a qual é responsável pela síntese de prostaglandinas envolvidas na resposta inflamatória (Clària, 2003). A IL-10, uma citocina anti-inflamatória e um fator modulador da ativação de macrófagos durante uma infecção (Couper et al., 2008)(55), também foi induzida pelo Papacárie Duo ${ }^{\circledR}$, na presença ou não do LPS.

Nesse estudo, utilizamos o LPS como um indutor da resposta imuno-inflamatórias. 0 LPS pode induzir respostas inflamatórias e imunológicas do hospedeiro durante as infecções bacterianas. Muitas destas respostas podem ser atribuídas aos efeitos diretos de LPS ou pela produção de citocinas mediada pelo LPS (Movat et al, 1987;. Loppnow et at, 1990;. Weg et al., 1995). Porém, sobre a capacidade imunomodulatória do Papacárie Duo ${ }^{\circledR}$, na presença ou na ausência de LPS, não havia sido investigada previamente. Assim, o aumento na expressão gênica de Ptgs2 e I/10 encontrados neste estudo, em presença de LPS, indicam uma modulação da resposta inflamatória pelo Papacárie Duo ${ }^{\circledR}$. O fator de necrose tumoral alfa (TNF-a), uma citocina pró inflamatória secretada por macrófagos e também indutora da produção de nódulos de mineralização por células da polpa dentária isolada de dentes permanentes de humanos (Paula-Silva et al., 2009), não apresentou aumento significante em sua expressão. O mesmo ocorreu com a metaloproteinase da matriz 9 (MMP-9), uma enzima que apresenta um papel importante na patogênese da inflamação pulpar (Tsai et al., 2005; Accorsi-Mendonça et al., 2013).

Uma possível limitação deste trabalho, contudo, foi a não realização de ensaios como ELISA, Imunoistoquímica e Western blotting, que detectam proteínas, e que seriam interessantes, tendo em vista nossos resultados obtidos quanto à avaliação da expressão gênica. Nesse sentido, novas pesquisas devem ser realizadas na tentativa de investigar o efeito de Papacárie Duo ${ }^{\circledR}$ em outros tipos de células inflamatórias, bem como seus efeitos in vivo. 
Considerando as limitações inerentes a este estudo, demonstramos que o Papacárie Duo $^{\circledR}$ não alterou a proliferação de macrófagos, porém foi citotóxico à $5 \%$, mas não à $0,5 \%$. Interessantemente, o Papacárie Duo ${ }^{\circledR}$ modulou a ativação de macrófagos pela indução da expressão de Ptgs2 e I/10 pré-estimulados com LPS, sem alterar a expressão de Tnf e Mmp9. 

4. Conclusões 



\section{CONCLUSÕES}

Em células indiferenciadas da polpa dentária (OD-21), o Papacárie Duo ${ }^{\circledR}$ foi ser citotóxico dependendo da concentração empregada, não influenciou a proliferação celular e apresentou um efeito inibitório na diferenciação celular. Especificamente, o Papacárie Duo ${ }^{\circledR}$ inibiu a expressão gênica do fator de transcrição RUNX2 (Runx2) e da sialoproteína óssea (Ibsp), importantes para a diferenciação celular e mineralização, porém estimulou a expressão de osteopontina (Spp1), uma proteína envolvida no metabolismo de tecidos mineralizados e reguladora da resposta imune.

Em macrófagos, os efeitos citotóxicos do Papacárie Duo ${ }^{\circledR}$ foram semelhantes às células da polpa dental, ou seja, foi citotóxico à $5 \%$, mas não à $0,5 \%$. Do mesmo modo, o Papacárie Duo ${ }^{\circledR}$ não alterou a proliferação celular. Interessantemente, o Papacárie Duo ${ }^{\circledR}$ inibiu a expressão do gene Ptgs2 que codifica a enzima ciclo-oxigenase-2 e induziu a expressão do gene $I / 10$ que codifica a interleucina-10. Quando pré-estimulados com LPS, o Papacárie Duo ${ }^{\circledR}$ novamente induziu a expressão de $I / 10$ e, interessantemente, apresentou um efeito indutor na produção de Ptgs2, à diferença do que foi observado em macrófagos não estimulados com LPS. Por outro lado, Tnf e Mmp9 não foram modulados pelo Papacárie Duo ${ }^{\circledR}$, na presença ou não de LPS. 

Referências 



\section{REFERÊNCIAS}

1. Abd-Elmeguid A, Yu DC. Dental pulp neurophysiology: part 1. Clinical and diagnostic implications. J Can Dent Assoc. 2009;75(1):55-9.

2. Accorsi-Mendonça T, Silva EJ, Marcaccini AM, Gerlach RF, Duarte KM, Pardo AP, et al. Evaluation of gelatinases, tissue inhibitor of matrix metalloproteinase-2, and myeloperoxidase protein in healthy and inflamed human dental pulp tissue. J Endod. 2013;39(7):879-82.

3. Beeley JA, Yip HK, Stevenson AG. Chemochemical caries removal: a review of the techniques and latest developments. Br Dent J. 2000;188(8):427-30.

4. Bleicher F. Odontoblast physiology. Exp Cell Res. 2014;325(2):65-71.

5. Bohari MR, Chunawalla YK, Ahmed BM. Clinical evaluation of caries removal in primary teeth using conventional, chemomechanical and laser technique: an in vivo study. J Contemp Dent Pract. 2012;13(1):40-7.

6. Bussadori SK, Castro LC, Galvão AC. Papain gel: a new chemo-mechanical caries removal agent. J Clin Pediatr Dent. 2005;30(2):115-9.

7. Cavalcanti BC, Costa-Lotufo LV, Moraes MO, Burbano RR, Silveira ER, Cunha KM, et al. Genotoxicity evaluation of kaurenoic acid, a bioactive diterpenoid present in Copaiba oil. Food Chem Toxicol. 2006;44(3):388-92.

8. Charadram N, Austin C, Trimby P, Simonian M, Swain MV, Hunter N. Structural analysis of reactionary dentin formed in response to polymicrobial invasion. J Struct Biol. 2013;181(3):207-22.

9. Chatakun P, Núñez-Toldrà R, Díaz López EJ, Gil-Recio C, Martínez-Sarrà E, HernándezAlfaro $F$, et al. The effect of five proteins on stem cells used for osteoblast differentiation and proliferation: a current review of the literature. Cell Mol Life Sci. 2014;71(1):113-42.

10. Chmilewsky F, Jeanneau C, Dejou J, About I. Sources of dentin-pulp regeneration signals and their modulation by the local microenvironment. J Endod. 2014;40(4 Suppl):S19-25.

11. Chogle SM, Goodis HE, Kinaia BM. Pulpal and periradicular response to caries: current management and regenerative options. Dent Clin North Am. 2012;56(3):521-36.

12. Chowdhry S, Saha S, Samadi F, Jaiswal JN, Garg A, Chowdhry P. Recent vs Conventional Methods of Caries Removal: A Comparative in vivo Study in Pediatric Patients. Int J Clin Pediatr Dent. 2015;8(1):6-11.

13. Clària J. Cyclooxygenase-2 biology. Curr Pharm Des. 2003;9(27):2177-90.

14. Cooper PR, Takahashi Y, Graham LW, Simon S, Imazato S, Smith AJ. Inflammationregeneration interplay in the dentine-pulp complex. J Dent. 2010;38(9):687-97. 
15. Costa CA, Ribeiro AP, Giro EM, Randall RC, Hebling J. Pulp response after application of two resin modified glass ionomer cements (RMGICs) in deep cavities of prepared human teeth. Dent Mater. 2011;27(7):e158-70.

16. Couper KN, Blount DG, Riley EM. IL-10: the master regulator of immunity to infection. J Immunol. 2008;180(9):5771-7.

17. Daltoé MO, Paula-Silva FW, Faccioli LH, Gatón-Hernández PM, De Rossi A, Bezerra Silva LA. Expression of Mineralization Markers during Pulp Response to Biodentine and Mineral Trioxide Aggregate. J Endod. 2016;42(4):596-603.

18. de Azevedo $\mathrm{CL}$, Marques MM, Bombana AC. Cytotoxic effects of cyanoacrylates used as retrograde filling materials: an in vitro analysis. Pesqui Odontol Bras. 2003;17(2):113-8.

19. D'Souza RN, Aberg T, Gaikwad J, Cavender A, Owen M, Karsenty G, et al. Cbfa1 is required for epithelial-mesenchymal interactions regulating tooth development in mice. Development. 1999;126(13):2911-20.

20. Duque C, Hebling J, Smith AJ, Giro EM, Oliveira MF, de Souza Costa CA. Reactionary dentinogenesis after applying restorative materials and bioactive dentin matrix molecules as liners in deep cavities prepared in nonhuman primate teeth. J Oral Rehabil. 2006;33(6):452-61.

21. Ericson D, Zimmerman M, Raber H, Götrick B, Bornstein R, Thorell J. Clinical evaluation of efficacy and safety of a new method for chemo-mechanical removal of caries. A multi-centre study. Caries Res. 1999;33(3):171-7.

22. Farges JC, Alliot-Licht B, Renard E, Ducret M, Gaudin A, Smith AJ, et al. Dental Pulp Defence and Repair Mechanisms in Dental Caries. Mediators Inflamm. 2015;2015:230251.

23. Fusayama T. Two layers of carious dentin; diagnosis and treatment. Oper Dent. 1979;4(2):63-70.

24. Ganss B, Kim RH, Sodek J. Bone sialoprotein. Crit Rev Oral Biol Med. 1999;10(1):79-98.

25. Garcia-Contreras R, Scougall-Vilchis RJ, Contreras-Bulnes R, Kanda Y, Nakajima $H$, Sakagami H. Cytotoxicity and pro-inflammatory action of chemo-mechanical cariesremoval agents against oral cells. In Vivo. 2014;28(4):549-56.

26. Goldman M, Kronman JH. A preliminary report on a chemomechanical means of removing caries. J Am Dent Assoc. 1976;93(6):1149-53.

27. Hamama H, Yiu C, Burrow MF, King NM. Systematic Review and Meta-Analysis of Randomized Clinical Trials on Chemomechanical Caries Removal. Oper Dent. 2015;40(4):E167-78.

28. Han N, Zheng $Y$, Li R, Li X, Zhou M, Niu Y, et al. $\beta$-catenin enhances odontoblastic differentiation of dental pulp cells through activation of Runx2. PLoS One. 2014;9(2):e88890. 
29. Huang FM, Li YC, Lee SS, Chang YC. Cytotoxicity of dentine bonding agents on human pulp cells is related to intracellular glutathione levels. Int Endod J. 2010;43(12):1091-7.

30. KIMMEL JR, SMITH EL. Crystalline papain. I. Preparation, specificity, and activation. J Biol Chem. 1954;207(2):515-31.

31. KIMMEL JR, SMITH EL. The properties of papain. Adv Enzymol Relat Subj Biochem. $1957 ; 19: 267-334$.

32. Komori T. Regulation of bone development and extracellular matrix protein genes by RUNX2. Cell Tissue Res. 2010;339(1):189-95.

33. Kuhn $E$, Chibinski AC, Reis A, Wambier DS. The role of glass ionomer cement on the remineralization of infected dentin: an in vivo study. Pediatr Dent. 2014;36(4):E118-24.

34. Loppnow $H$, Libby $P$, Freudenberg M, Krauss JH, Weckesser J, Mayer H. Cytokine induction by lipopolysaccharide (LPS) corresponds to lethal toxicity and is inhibited by nontoxic Rhodobacter capsulatus LPS. Infect Immun. 1990;58(11):3743-50.

35. Maragakis GM, Hahn P, Hellwig E. Chemomechanical caries removal: a comprehensive review of the literature. Int Dent J. 2001;51(4):291-9.

36. Marshall GW, Marshall SJ, Kinney JH, Balooch M. The dentin substrate: structure and properties related to bonding. J Dent. 1997;25(6):441-58.

37. Martins MD, Fernandes KP, Motta LJ, Santos EM, Pavesi VC, Bussadori SK. Biocompatibility analysis of chemomechanical caries removal material Papacárie on cultured fibroblasts and subcutaneous tissue. J Dent Child (Chic). 2009;76(2):123-9.

38. Massara ML, Alves JB, Brandão PR. Atraumatic restorative treatment: clinical, ultrastructural and chemical analysis. Caries Res. 2002;36(6):430-6.

39. Metzger Z. Macrophages in periapical lesions. Endod Dent Traumatol. 2000;16(1):1-8.

40. Mosmann T. Rapid colorimetric assay for cellular growth and survival: application to proliferation and cytotoxicity assays. J Immunol Methods. 1983;65(1-2):55-63.

41. Movat HZ, Cybulsky MI, Colditz IG, Chan MK, Dinarello CA. Acute inflammation in gramnegative infection: endotoxin, interleukin 1 , tumor necrosis factor, and neutrophils. Fed Proc. 1987;46(1):97-104.

42. Murray PE, Lumley PJ, Ross HF, Smith AJ. Tooth slice organ culture for cytotoxicity assessment of dental materials. Biomaterials. 2000;21(16):1711-21. 
43. Murray PJ, Wynn TA. Protective and pathogenic functions of macrophage subsets. Nat Rev Immunol. 2011;11(11):723-37.

44. Nagl M, Nguyen VA, Gottardi W, Ulmer H, Höpfl R. Tolerability and efficacy of Nchlorotaurine in comparison with chloramine $\mathrm{T}$ for the treatment of chronic leg ulcers with a purulent coating: a randomized phase II study. Br J Dermatol. 2003;149(3):5907.

45. Ogata Y. Bone sialoprotein and its transcriptional regulatory mechanism. J Periodontal Res. 2008;43(2):127-35.

46. Okiji T, Kawashima N, Kosaka T, Matsumoto A, Kobayashi C, Suda H. An immunohistochemical study of the distribution of immunocompetent cells, especially macrophages and Ia antigen-expressing cells of heterogeneous populations, in normal rat molar pulp. J Dent Res. 1992;71(5):1196-202.

47. Orchardson R, Cadden SW. An update on the physiology of the dentine-pulp complex. Dent Update. 2001;28(4):200-6, 8-9.

48. Pagel CN, Wasgewatte Wijesinghe DK, Taghavi Esfandouni N, Mackie EJ. Osteopontin, inflammation and myogenesis: influencing regeneration, fibrosis and size of skeletal muscle. J Cell Commun Signal. 2014;8(2):95-103.

49. Pashley $\mathrm{DH}$, Carvalho RM. Dentine permeability and dentine adhesion. J Dent. 1997;25(5):355-72.

50. Paula-Silva FW, Ghosh A, Arzate H, Kapila S, da Silva LA, Kapila YL. Calcium hydroxide promotes cementogenesis and induces cementoblastic differentiation of mesenchymal periodontal ligament cells in a CEMP1- and ERK-dependent manner. Calcif Tissue Int. 2010;87(2):144-57.

51. Paula-Silva FW, Ghosh A, Silva LA, Kapila YL. TNF-alpha promotes an odontoblastic phenotype in dental pulp cells. J Dent Res. 2009;88(4):339-44.

52. Saito K, Nakatomi M, Ida-Yonemochi H, Kenmotsu S, Ohshima H. The expression of GMCSF and osteopontin in immunocompetent cells precedes the odontoblast differentiation following allogenic tooth transplantation in mice. J Histochem Cytochem. 2011;59(5):518-29.

53. Saito K, Nakatomi M, Ida-Yonemochi H, Ohshima H. Osteopontin Is Essential for Type I Collagen Secretion in Reparative Dentin. J Dent Res. 2016.

54. Scatena M, Liaw L, Giachelli CM. Osteopontin: a multifunctional molecule regulating chronic inflammation and vascular disease. Arterioscler Thromb Vasc Biol. 2007;27(11):2302-9.

55. Schmalz G. Use of cell cultures for toxicity testing of dental materials--advantages and limitations. J Dent. 1994;22 Suppl 2:S6-11. 
56. Téclès O, Laurent P, Zygouritsas S, Burger AS, Camps J, Dejou J, et al. Activation of human dental pulp progenitor/stem cells in response to odontoblast injury. Arch Oral Biol. 2005;50(2):103-8.

57. Tsai $\mathrm{CH}$, Chen $\mathrm{YJ}$, Huang FM, Su YF, Chang YC. The upregulation of matrix metalloproteinase-9 in inflamed human dental pulps. J Endod. 2005;31(12):860-2.

58. Weg VB, Walsh DT, Faccioli LH, Williams TJ, Feldmann M, Nourshargh S. LPS-induced 111In-eosinophil accumulation in guinea-pig skin: evidence for a role for TNF-alpha. Immunology. 1995;84(1):36-40.

59. Yalvac ME, Ramazanoglu M, Rizvanov AA, Sahin F, Bayrak OF, Salli U, et al. Isolation and characterization of stem cells derived from human third molar tooth germs of young adults: implications in neo-vascularization, osteo-, adipo- and neurogenesis. Pharmacogenomics J. 2010;10(2):105-13.

60. Yang F, Xu N, Li D, Guan L, He Y, Zhang Y, et al. A feedback loop between RUNX2 and the E3 ligase SMURF1 in regulation of differentiation of human dental pulp stem cells. J Endod. 2014;40(10):1579-86. 